Pedrini, A.G.; Messas, T.P.; Pereira, E.S.; Ghilardi-Lopes, N.P.; Berchez, F.A. Educação Ambiental pelo Ecoturismo numa trilha marinha no Parque Estadual da llha Anchieta, Ubatuba (SP). Revista Brasileira de Ecoturismo, São Paulo, v.3, n.3, 2010, pp.428-459.

\title{
Educação Ambiental pelo Ecoturismo numa trilha marinha no Parque Estadual da Ilha Anchieta, Ubatuba (SP)
}

\author{
Alexandre de Gusmão Pedrini, Tatiana Pinto Messas, Eugênia da \\ Silva Pereira, Natalia Pirani Ghilardi-Lopes, Flávio Augusto Berchez
}

\section{RESUMO}

A Avaliação da Educação Ambiental busca atestar se o turismo ecológico muda hábitos, posturas e condutas. A restrição temporal de um percurso ecoturístico por trilhas marinhas impede uma adequada inserção da Educação Ambiental para Sociedades Sustentáveis (EASS). É apresentada uma atividade de EASS, no contexto do Projeto EcoTurisMar (Educação Ambiental pelo Ecoturismo Marinho em Áreas Protegidas) ocorrida na Trilha Marinha da Praia do Presídio, Parque Estadual da Ilha Anchieta (PEIA), Ubatuba, São Paulo, no pico da visitação de verão. Constou de: a) Inscrição detalhada; b) Entrevista de Avaliação Pré-Teste; c) Assinatura de Termo de Declaração de Saúde; d) Preleções contextualizadas (em terra) sobre: 1) Composição da Geobiodiversidade; 2) Exemplo de Teia Alimentar Submarina; e) Seleção do equipamento de mergulho; f) Transporte da balsa pelos participantes para partida na praia; g) Aquecimento físico; h) Contemplação do mar e expressão dessa emoção; i) sensibilização na água com colocação do equipamento de mergulho; j) Percurso na trilha em quatro áreas interpretativas, abordando: 1) identificação da geobiodiversidade; 2) observação de inter-relações tróficas; 3) diálogo sobre questões socioambientais com efeitos globais/locais; 4) síntese integradora final; k) Realização de entrevista para o Pós-Teste e avaliação da atividade; I) Retorno dos monitores, por mar, ao ponto inicial, empurrando a balsa e o material de mergulho emprestado aos ecoturistas. Resultados da avaliação: a) aumento significativo $(p=0,001)$ da percepção da contribuição do mar através das microalgas que nele vivem pela disponibilização do excesso de oxigênio que elas produzem para a respiração de outros seres existentes no planeta; b) alteração da pré-concepção dos ecoturistas sobre a biodiversidade em uma UC e a maior percepção de organismos do costão como as macroalgas e os ouriços; c) aumento significativo $(p=0,046)$ da percepção da "Degradação Humana" como principal impacto negativo no mar; d) noção do ecoturista de que os principais impactos negativos do PEIA eram tanto de origem tecnológica (Lixo, Esgoto e Óleo) como do próprio ecoturista ao tocar e mexer nos organismos marinhos; e) aumento significativo $(p=0,025)$ da percepção de "Preservação/conservação" como forma de minimizar o impacto ambiental negativo humano e como principal atividade da EASS; $f)$ aumento significativo $(p=0,000)$ no número de conexões para cada compartimento socioambiental e no seu total, indicando entendimento da interdependência do meio ambiente. A proposta EcoTurisMar apresentou resultados que a configuram como factível para proporcionar sensibilização e aquisição de novos conceitos/posturas para uma percepção/interpretação adequada do mar através do ecoturismo.

PALAVRAS-CHAVE: Ecoturismo Marinho; Educação Ambiental; Trilha; Unidade de Conservação. 


\section{Environmental Education for the Ecotourism on a Marine Trail in the Parque Estadual da Ilha Anchieta, Ubatuba, SP, Brazil.}

\section{ABSTRACT}

The evaluation of Environmental Education aims at verifying whether ecological tourism changes people's habits, attitudes and manners. Time restrictions of ecotouristic routes in marine trails prevent an adequate insertion of the Environmental Education for Sustainable Societies (EESS). An EESS activity is presented in the context of the EcoTurisMar Project (Marine Ecotourism Environmental Education in Protected Areas), which took place in Presídio Beach, Parque Estadual da Ilha Anchieta (PEIA), Ubatuba, São Paulo, in the highest of summer visiting. It was constituted of: a) detailed registration; b) pre-test interview; c) completion of a Health Declaration Term; d) contextualized lectures (on land) about: 1) geobiodiversity composition; 2) example of marine trophic web; e) selection of diving equipment; f) ferry boats for the participants leaving the beach; g) warm-ups; $h$ ) sea contemplation and expression of emotions; i) water sensitizing and gearing of diving equipment; j) trail routing in four interpretative areas, mentioning: 1) geobiodiversity identification; 2) observation of trophic relations; 3) dialogue about socioenvironmental questions with local/global effects; 4) integrative synthesis; k) post-test interview and evaluation of the activity; I) return of the monitors, by the sea, to the initial point, carrying the raft and the equipment borrowed by the ecotourists. Evaluation results: a) significant increase $(p=0,001)$ of the perception of sea contribution to the respiration of other existing living beings on the planet, through the disposal of oxygen excess produced by inhabitant microalgae; $b$ ) alteration of the ecotourists' preconception about biodiversity in a Conservation Unit and increased perception of rocky shore organisms, such as macroalgae and sea urchins; c) significant increase $(p=0,046)$ in the perception of "Anthropogenic degradation" as the main negative impact in the sea; d) ecotourists' notion that the main negative impacts in PEIA had their origins not only in technological products (Trash, Sewage, Oil) but also in ecotourism, because of touching marine organisms; e) significant increase $(p=0,025)$ in the perception of "Preservation/conservation" as a way of minimizing negative anthropogenic environmental impact and as the EESS main activity; f) significant increase $(p=0,000)$ in the number of connections to each socioenvironmental compartment and in their total, indicating the understanding of the interdependence of the environmental components. EcoTurisMar's proposal presented results that configure it as effective to provide sensitizing and acquisition of new concepts/manners for an adequate perception/interpretation of the sea through ecotourism

KEYWORDS: Marine Ecotourism; Environmental Education; Trail; Protect Area.

\section{Introdução}

O ambiente planetário vem se deteriorando paulatinamente e o ecoturismo emerge com uma das propostas alternativas capazes de uso público do meio natural, proporcionando atividades com compartilhamento local dos benefícios e não só os malefícios como geralmente vem ocorrendo. O ecoturismo se opõe ao turismo tradicional massificante e concentrador dos benefícios apenas a empresários alóctones e atribuição ao meio autóctone dos seus malefícios. O ecoturismo tem em seu bojo conceitual premissas como: a) envolvimento comunitário local de onde o ecoturismo será 
realizado; b) promoção a interpretação e/ou educação ambiental de modo que a atividade capacite as pessoas a mudarem seus hábitos predatórios por conservacionistas do ambiente ecoturístico; c) composição de pequenos grupos preferencialmente personalizados; d) promoção da proteção às unidades de conservação através de atividades com mínimo impacto (HONEY, 1999).

O ecoturismo terrestre é bastante desenvolvido no mundo e também no Brasil, entretanto o marinho é praticamente inexistente a despeito de sua imensa zona costeira, apesar do turismo marinho ser muito praticado. O tradicional turismo marinho brasileiro tem sido altamente prejudicial na suas mais variadas formas, como o merguIho recreacional. Suas atividades vêm gerando sérios impactos negativos (AUGUSTOWSKI; FRANCINE Jr, 2002), principalmente em áreas protegidas, e o ecoturismo surge como a única possibilidade de turismo não predatório.

O presente artigo apresenta uma proposta de EA pelo ecoturismo marinho realizado numa trilha subaquática, tendo por cenário a Trilha Marinha da Praia do Presídio, Parque Estadual da llha Anchieta (PEIA), município de Ubatuba, estado de São Paulo. Propõe também estratégias de avaliação da EA nesse contexto.

\section{Referencial Teórico}

\subsection{A Educação Ambiental}

A Educação Ambiental (EA) vem sendo praticada em todo o mundo, pois ela possui arsenal conceitual e prático para que se modifiquem os hábitos predadores e consumistas da sociedade capitalista. O paradigma da EA nacional é a Educação Ambiental para Sociedades Sustentáveis (EASS) - referencial dos educadores ambientais brasileiros (NEIMAN, 2007; PEDRINI, 2007). Ela tem seus preceitos no Tratado de Educação Ambiental para Sociedades Sustentáveis e Responsabilidade Global (TEASS) que se transformou em política pública pela segunda versão do ProNEA (BRASIL, 2005). Para tal, vários pleitos científicos da EA pelo ecoturismo foram sintetizados por Pedrini (2006) e então a trilha para a qual a EASS fosse adotada teria que apresentar/ser: a) abrangência de um espaço geográfico natural/construído; b) planejada cuidadosa e participativamente com todos os atores sociais do contexto; c) monitorada para sua manutenção e recuperação de equipamentos; d) identificação dos impactos antrópicos e naturais para sua mitigação ou extinção; e) caracterização dos componentes abióticos (por ex. geodiversidade) e bióticos (por ex. biodiversidade); f) publicidade de seus bens ambientais ao longo do percurso. Por conseguinte, a EASS numa trilha ecoturística deveria ser: a) emancipatória, em que o ecoturista adquira informações e habilidades para enfrentar e resolver problemas socioambientais; b) transformadora, em que o ecoturista seja estimulado a mudar seus hábitos, atitudes e condutas para a construção de sociedades sustentáveis; c) globalizadora, em que o ecoturista seja capaz de entender a conexão local e global do ambiente; d) contextualizadora, em que o ecoturista aprenda a partir dos conhecimentos locais; e) ética, em que os ecoturistas respeitem todas as manifestações de vida na Terra. Assim, a práti- 
ca de EA em trilhas ecoturísticas terá qualidade conceitual se atender às características apresentadas.

No campo da Educação Ambiental Marinha e Costeira (EAMC) no Brasil, Pedrini (2010) apresentou uma tipologia que tenta sintetizar o que vem sendo realizado ao longo do litoral brasileiro. O Quadro I apresenta essas tendências recentes e um exemplo emblemático de cada uma delas.

Quadro I - Tipologias de Educação Ambiental Marinha no Brasil e exemplos de autores emblemáticos (adaptado de PEDRINI, 2010).

\begin{tabular}{|c|c|}
\hline Tipologia & Autores Emblemáticos \\
\hline $\begin{array}{c}\text { a) através de espécies/organismos-bandeira, } \\
\text { ícones ou carismáticos; }\end{array}$ & Silva-Jr. et al. (2010) - golfinho-rotador \\
\hline $\begin{array}{c}\text { b) em função de variados ecossistemas marinhos } \\
\text { e costeiros; }\end{array}$ & Prates et al. (2007) - recifes de coral \\
\hline c) para diferentes públicos; & Ghilardi e Berchez (2010) - ecoturistas \\
\hline $\begin{array}{c}\text { d) baseados em simulacros da realidade como } \\
\text { aquários ou oceanários; }\end{array}$ & Gallo Neto e Barbosa (2010) - aquário de Ubatuba (SP) \\
\hline e) como aulas de biologia marinha; & Victal (2010) - Projeto Berçários Marinhos \\
\hline
\end{tabular}

Como observado no Quadro I há várias atividades com múltiplos públicos que são comumente denominadas de EA e, portanto, demandam urgentes avaliações para se verificar se de fato mudam hábitos e emancipam o cidadão e/ou suas comunidades como prevê a EASS.

\subsection{As Unidades de Conservação no Brasil}

As Unidades de Conservação (UCs) no Brasil, em especial parques, necessitam compatibilizar a conservação da natureza com o seu uso público. Essas demandas são fundamentais para a comunidade humana, pois, por um lado garantem sustentabilidade ambiental e, por outro lado, permitem que a Interpretação e a Educação Ambientais e o ecoturismo possam ser realizados com o fim de retroalimentar a aludida sustentabilidade ambiental (DELGADO, 2000). Porém, essas áreas protegidas, embora sejam em número considerável em qualquer nível governamental, ou seja, federal, estadual, municipal ou ainda o privado não vêm recebendo atenção adequada pela maioria de seus gestores (STEINER et al., 2006).

As UCs são criadas rotineiramente no Brasil sem que tenham condições de funcionar como as unidades marinhas e costeiras. Pereira (1999) sistematizou as informações relativas às unidades de conservação das zonas costeira e marinha do Brasil, encontrando 255 unidades de conservação. Elas representam cerca de 17 miIhões de hectares, sem contar as 34 reservas indígenas que chegam perto de 600 mil hectares. Esses dados representam cerca de 8\% do território brasileiro, porém todas têm sérios problemas fundiários e de ocupação irregular, sendo que algumas delas foram criadas em locais povoados e de propriedade privada sem que sejam realizadas consultas aos atores sociais que serão atingidos pela UC. Assim, além da visita- 
ção turística que impacta negativamente as UCs elas também já têm problemas internos de conservação ambiental (PRATES, 2006; STEINER, et al., 2006). Muitas vezes, desconhece-se o patrimônio natural geral que é usado para justificar a criação de uma UC e apenas com pesquisas posteriores é que de fato se conhecerá detalhes da funcionalidade da geobiodiversidade local.

Para se realizar o ecoturismo costeiro e marinho é necessário que se disponibilize o conhecimento sobre o meio marinho brasileiro nas UCs. Esse conhecimento não se restringe apenas à composição taxonômica de sua geobiodiversidade (AMARAL; JABLONSKI, 2005; PRATES; LIMA, 2008). Porém, considerando-se apenas as informações taxonômicas de UCs há entraves a considerar: a) os nomes científicos, via de regra, mudam com frequência; b) muitos dos inventários taxonômicos são de décadas atrás, compondo-se de informações desatualizadas; c) raramente estão cobertos todos os filos taxonômicos; d) grande parte das informações e dados taxonômicos estão dispersos na literatura científica internacional estrangeira face às exigências estatais de financiamento de pesquisa que exigem a publicação em periódicos internacionais, sendo necessário pagar em moeda estrangeira para acessar a informação; e) cerceamento e criação de entraves para que cientistas façam estudos socioambientais e obtenham sua licença de pesquisa. Muitas vezes, burocratas estatais com limitado conhecimento sobre a ciência marinha e também não fazendo o menor esforço em conhecer e entender as exigências científicas complicam mais ainda o levantamento de dados e informações de cada área protegida. Muitas vezes cientistas vão fazendo seus estudos antes da concessão da licença, pois os fenômenos naturais não podem esperar pela burocracia estatal, levando algumas até meses para concedê-las. E assim, muitos dos efeitos ambientais negativos sobre a biodiversidade marinha de unidades de conservação são pouco conhecidos em cada UC e por modalidade de impacto (PEDRINI, et al., 2009). Essas dificuldades de caracterização e acesso à informação pretérita e atual da geobiodiversidade brasileira marinha complicam mais ainda um lastimável e insolúvel problema brasileiro: a perda dos bens ambientais (muitas vezes desconhecidos ainda para a ciência e a sociedade) pelo mal uso publico e má gestão estatal da maioria das unidades de conservação marinha e costeira brasileiras.

É condição fundamental que seja caracterizada a geobiodiversidade das UCs marinhas e costeiras para que se possa implementar o ecoturismo, além de sua aplicação em Planos de Manejo. Porém, não é possível se esperar que haja pesquisas biológicas, geológicas e oceanográficas prévias em todas as UCs para o desenvolvimento do ecoturismo marinho nas UCs. Desse modo, é desejável que nessas equipes haja cientistas taxonômicos trabalhando na equipe ou em estreita cooperação com turismólogos.

\subsection{O ecoturismo em UCs}

O ecoturismo, no Brasil, vem sendo praticado essencialmente em UCs. O (eco) turismo marinho e costeiro, segundo Miller (1993) envolveu cerca de 50 milhões de 
visitantes na década de 1990, apenas no Oceano Pacífico. É um fenômeno que não pode passar despercebido na sociedade. Porém, tal como o turismo tradicional o ecoturismo pode propiciar impactos indesejados em UCs (RUSCHMANN, 1993; REUSS-STRENGEL, et al., 1997). Apesar de seu propósito ser de uma prática compatibilizada com a conservação e/ou preservação ambiental nem sempre essas premissas vem sendo adotadas. Um trabalho clássico no meio marinho baseado nos pressupostos de Barros e Dines (2000) foi desenvolvido pelo Ministério do Meio Ambiente (PRATES, et al., 2007). É a "Campanha de Conduta Consciente em Ambientes Recifais" e objetiva diminuir a exploração, impacto e destruição de estruturas coralíneas na costa nordeste brasileira. Recentemente, o ecoturismo vem sendo alardeado como a solução para uma visitação racionalizada e com sustentabilidade ambiental em UCs. Ele se opõe ao turismo massificado das grandes corporações empresariais do turismo internacional que usam o turismo para excluir socialmente as comunidades que recebem os turistas (SALES; ANTONIO FILHO, 2008). Serrano (2000), porém, já destacava que o ecoturismo estava perdendo sua capacidade crítica, pois naquela época ele já estava copiando as práticas desastrosas do turismo tradicional massificante ao propor pacotes para consumo rápido e fácil. Ou seja, empresários se aproveitam da demanda pública por um turismo na natureza conservada (principalmente UCs) e na realidade eles apenas se apropriaram da atividade ecoturística para se beneficiar economicamente por essa busca, oferecendo apenas passeios tradicionais no ambiente silvestre.

A proposta conceitual do ecoturismo nega a massificação excludente do turismo predatório, como, por exemplo, aquele promovido pelos transatlânticos em grande escala, ou em menor escala pelas escunas que levam dezenas de pessoas por dia a várias UCs costeiras e marinhas brasileiras. Exemplo contemporâneo é a invasão proporcionada por navios enormes que transportam centenas de pessoas diariamente para a Área de Proteção Ambiental Marinha de Armação de Búzios, no Estado do Rio de Janeiro. Essa espetacularização consumista do ecoturismo possibilita o exercício da massificação em suas ações, contrariando assim suas prerrogativas conceituais (HINTZE, 2008).

Porém, o governo federal sempre aponta o ecoturismo como única solução para o turismo em UCs. Serrano e Paes-Luchiari (2005) comentam que há esforços muito tímidos por parte do governo federal em termos de amplas atividades de ecoturismo, pois suas ações (se existem) são praticamente invisíveis à sociedade brasileira. Uma das ações do Ministério do Turismo no contexto do ecoturismo foi a criação de vários pólos pelo Brasil. No entanto, Serrano e Paes-Luchiari (op. cit.) alertam para a necessidade urgente de se avaliar esses pólos que são na maioria em UCs. Exemplificam com o Pólo Ecoturístico de Lagamar no Estado de São Paulo que, a despeito de suas metas (há mais de cincos anos) terem sido de participação comunitária e desenvolvimento regional, pouco conseguiram ainda nessa linha. Porém, o mais alarmante, segundo os autores supracitados é que apesar de constar nas políticas públicas que só pode receber apoio público financeiro caso haja desenvolvimento local e a regionalização do ecoturismo, os investimentos federais não levam esses pressupostos em consideração. De fato, o governo federal tem priorizado essencialmente o turismo internacional e não o nacional.

Atualmente, o ecoturismo tem evoluído dentre suas várias manifestações para uma construção coletiva através de arranjos produtivos locais que são um dos desdobra- 
mentos, na nossa percepção, do conceito de "clusters ecoturísticos". Segundo Barbosa e Zamboni (2001) e Coriolano et al. (2009) esses arranjos congregam os principais atores sociais de um local ou região interessados em desenvolver um ecoturismo verdadeiramente sustentável de longo prazo. Esses atores poderiam ser exemplificados como agências de turismo, meios de hospedagem, restaurantes, lojas, universidades e coletivos empresariais. Porém, no nosso entendimento devem ser acrescidos os governos municipais, os gestores de UCs, os conselhos das UCs envolvidas, as Organizações NãoGovernamentais (ONGs) socioambientais e os coletivos de classes populares como pescadores, quilombolas, dentre outros segmentos desfavorecidos socialmente. Entendemos que essa é a tendência contemporânea de um ecoturismo verdadeiramente participativo e distribuidor de benefícios comunitários.

\subsection{Educação Ambiental em Trilhas Ecoturísticas}

O ecoturismo em trilhas terrestres com a prática de educação ou interpretação ambiental é assunto trivial no Brasil (FIGUEIREDO, 1999; COSTA; COSTA, 2005; NEIMAN, 2007). Há grande debate sobre a qualidade da Educação Ambiental (EA) ou Interpretação Ambiental (IA) praticada nesse contexto já que o tempo do percurso na trilha é curtíssimo para se promover uma mudança de hábitos, condutas ou posturas (NEIMAN, 2007). Recentemente, as trilhas vêm recebendo atenção como área de pesquisa de modo emblemático por Costa (2006) e Neiman (2007), porém no ambiente terrestre. Em termos de trilhas marinhas há limitadíssimos trabalhos sobre o tema no país, possivelmente pela inexistência da prática de ecoturismo marinho, apesar do imenso litoral brasileiro. A própria metodologia para se implantar trilhas marinhas tem, no Brasil, o trabalho emblemático de Wegner (2002), do qual derivaram outros como os que podem ser visualizados no Quadro II. Nele estão relacionadas as únicas menções sobre trilhas marinhas no Brasil dirigidos tanto para a EA como para o ecoturismo marinho.

Como visto no Quadro II a maioria absoluta da adoção de trilhas marinhas é para atividades com caráter ecoturista existentes na região sul e sudeste do Brasil. Para que as atividades possam ser realizadas nas trilhas é fundamental que haja caracterização de sua geobiodiversidade e na área de EA no mar há duas obras emblemáticas brasileiras: a) manual de Ghilardi et al. (2007) para costões da região sudeste; b) livro de apoio do Projeto Coral Vivo por Gouveia (2008) para região nordeste.

Quadro II - Citações de relatos sobre trilhas marinhas no Brasil.

\begin{tabular}{|l|c|c|c|}
\hline \multicolumn{2}{|c|}{ Características } & \multicolumn{2}{c|}{ Finalidades } \\
\hline \multicolumn{1}{|c|}{ Autor } & Estado & $\begin{array}{c}\text { Essencialmente } \\
\text { Pedagógicas }\end{array}$ & $\begin{array}{c}\text { Essencialmente } \\
\text { Ecoturísticas }\end{array}$ \\
\hline Wegner (2002) & SC & & $\mathrm{X}$ \\
\hline Lima et al. (2006) & SC & & $\mathrm{X}$ \\
\hline Berchez et al. (2005) & SP & $\mathrm{X}$ & $\mathrm{X}$ \\
\hline Machado (2007) & SP & & \\
\hline
\end{tabular}




\subsection{A Avaliação da Educação Ambiental pelo Ecoturismo em UCs}

A Avaliação da Educação Ambiental no Ecoturismo (AEAE) abrange múltiplas dimensões. O mais comum no contexto internacional de UCs marinhas é a adoção do termo IA como no trabalho de Madin e Fenton (2004). Esses autores realizaram uma avaliação dos programas por eles chamados de Interpretação Ambiental Marinha (IAM) realizados no Parque Marinho da Grande Barreira de Corais na Austrália. Concluíram que estava havendo mudanças significativas nos turistas visitantes dos corais e que a metodologia de avaliação da eficácia dos programas de IAM poderia ser feita pelo envio de questionários. No Brasil, pode-se citar alguns trabalhos sobre EA em UCs (VASCONCELLOS, 1998; NOEBAUER, 2004; BERCHEZ, et al., 2005, 2007) e trilhas ecoturísticas (TABANEZ, et al., 1997; LIMA, et al., 2003).

Uma dificuldade frequente também é que raramente as publicações apresentam seus pressupostos de avaliação. Um exemplo, no contexto ecoturístico marinho é o trabalho de Lima et al. (2003) que avaliaram o desempenho de turistas numa trilha, mas não detalharam a abordagem conceitual e metodológica dela emanada, dificultando sua replicação e sua eventual recontextualização. Verifica-se, também, que, muitas vezes, a avaliação ao ser implementada não tem consequências e terminam sendo conhecimentos importantes academicamente, mas sem aparente aproveitamento nas práticas cotidianas da EA, apesar da demanda permanente por sua avaliação de qualidade. A avaliação da qualidade conceitual das atividades de EA em qualquer de seus contextos de aplicação, como o ecoturismo, também é praticamente desconhecida e geralmente é adotada em unidades de conservação. .

\section{O Parque Estadual da Ilha Anchieta.}

O Parque Estadual da llha Anchieta (PEIA) é uma Unidade de Conservação (UC) terrestre do estado de São Paulo, mas com entorno aquático por ser insular marinho. Sua zona de amortecimento marinha possui restrições de uso público, pois é a região mais procurada pelos turistas por ser visualmente linda e ainda quase primitiva (Figura 1). Cervantes et al. (1992) apresentam as diretrizes para o uso público da rede de parques sob a jurisdição do Instituto Florestal do Estado de São Paulo (IF-SP) que hoje pertence à Fundação Florestal e a qual está submetido o PEIA. Os dois objetivos gerais dessas diretrizes são: a) propiciar lazer, recreação e educação ambiental à comunidade humana; b) despertar nessa comunidade uma consciência crítica para a conservação ambiental nas/das UCs do IF-SP. Dentre os dezessete objetivos específicos, há alguns relatos publicados sobre o PEIA.

O uso público no PEIA nos seus diversos matizes como o turismo (em seus diversos segmentos na ilha) tem trazido impactos positivos como o pagamento da taxa de visitação, divulgação de sua rica história e a divulgação de seus bens naturais à sociedade. Porém, os efeitos negativos do turismo marinho têm causado situações irreversíveis de perigo ao ambiente marinho em outras UCs brasileiras (MITRAUD, 2001; KAWAMOTO Jr., 2005; MELO, et al., 2005), podendo o mesmo se repetir no PEIA. 
Pedrini, A.G.; Messas, T.P.; Pereira, E.S.; Ghilardi-Lopes, N.P.; Berchez, F.A.

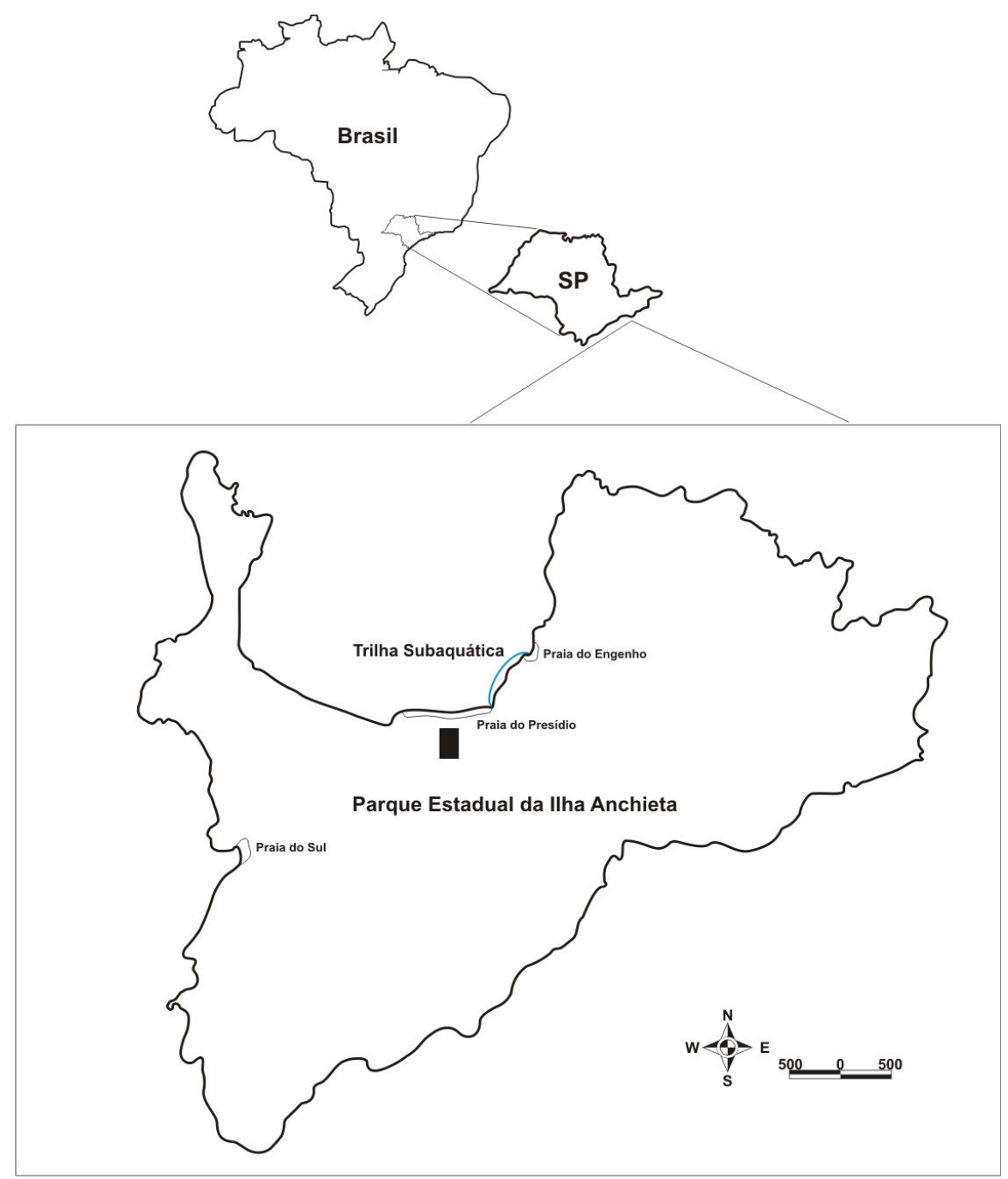

Figura 1 - Localização do Parque Estadual da Ilha Anchieta e Trilha Subaquática. Fonte: Robim et. al. 2004. (Modificado: Robim, 2008)

Anualmente, nos meses de janeiro, (quando ocorre o pico de visitação no PEIA) vem sendo realizado o projeto de extensão universitária "Trilha Subaquática - Educação Ambiental para Ecossistemas Marinhos" que já atendeu cerca de 6.000 visitantes (GHILARDI; BERCHEZ, 2010). Essa atividade está detalhadamente descrita no trabalho de Berchez et al. (2007), apresentando o mais importante trabalho de Educação Ambiental Marinha de base científica do Brasil. O Projeto TrilhaSub oferece seis atividades, sendo porém três as possibilidades realizadas diretamente no mar: a) trilha marinha com pontos interpretativos orientadas por monitores em mergulho livre equipado (snorkel) e base de apoio flutuante; b) trilha submarina orientadas por monitores em mergulho autônomo (SCUBA); c) piscina natural com monitores portando visores com fundo de vidro. Maiores informações podem ser obtidas no site: http:// www.ib.usp.br/ecosteiros. 


\section{Metodologia}

A Trilha Interpretativa Subaquática com Mergulho Livre (TISML) é onde se realizam as atividades de EAM com nado equipado (com auxílio de máscara, respirador"snorkel" e nadadeiras) do Projeto TrilhaSub (Figura 2).
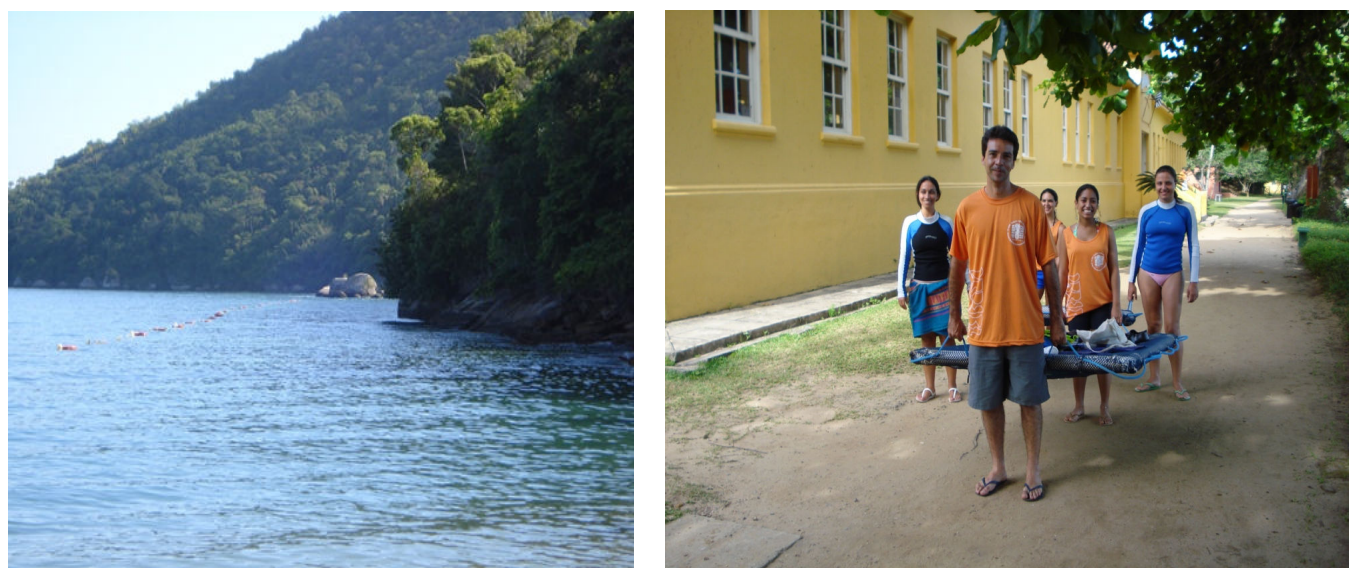

Figura 2 - Vista geral da área da trilha interpretativa marinha e da balsa de apoio com monitores e parte dos equipamentos utilizados indo para realizar a atividade Trilha Subaquática com Mergulho Livre (fotografias de Alexandre de Gusmão Pedrini).

\subsection{Operacionalização}

A atividade de EA pelo Mergulho Livre (ML) é feita através de nado equipado (máscara, respirador e nadadeiras) ao longo de uma trilha marinha de $350 \mathrm{~m}$ de costão, com 4-6 paradas em pontos de interpretação ambiental. É realizada em grupos máximos de 4 pessoas como forma de minimizar o impacto ambiental (BERCHEZ, et al., 2005, 2007). Dois monitores acompanham cada atividade, sendo um responsável principalmente pela condução e apresentação do ambiente e o outro, com menor experiência, pelo apoio. Acompanha o grupo uma balsa quadrada de apoio de $1,5 \mathrm{~m}$ de lado, constituída por tubos de PVC e garrafas PET e que se destinam tanto à segurança como a servir como uma plataforma de apoio para discussões e anotações (Figura 2). Maiores informações sobre esse e os outros modelos podem ser obtidas no trabalho de Berchez et al. (2007).

Os monitores são capacitados em curso teórico-prático na USP e no PEIA. Essa atividade é uma das possibilidades em teste que poderá ser a base que propiciará a construção coletiva de um produto ecoturístico comercial. Esse produto se propugna ser o mote para uma atividade permanente auto-sustentável da EASS pelo ecoturismo marinho em áreas protegidas. Toda a atividade leva, em média, cerca de $1 \mathrm{~h}$ e meia para ser realizada pelo ecoturismo em trilhas interpretativas marinhas (BERCHEZ, et al., 2007). A atividade foi realizada conforme está explicitado no Quadro III que apresenta as principais fases da atividade TrilhaSub comparadas a EcoTurisMar. 
Pedrini, A.G.; Messas, T.P.; Pereira, E.S.; Ghilardi-Lopes, N.P.; Berchez, F.A.

Quadro III - Principais fases das atividades de Mergulho Livre na Trilha Marinha dos Projetos TrilhaSub e EcoTurisMar.

\begin{tabular}{|c|c|c|c|}
\hline Fase & Atividade & $\begin{array}{c}\text { Projeto TrilhaSub } \\
\text { Tradicional } \\
\end{array}$ & $\begin{array}{c}\text { Proposta do Projeto Eco- } \\
\text { TurisMar }\end{array}$ \\
\hline 1 & Inscrição & Simples & Detalhada \\
\hline 2 & Entrevista de Pré-Teste & Ausente & Presente \\
\hline 3 & $\begin{array}{c}\text { Assinatura de Termo de Declaração de Saú- } \\
\text { de }\end{array}$ & \multicolumn{2}{|c|}{ Presente } \\
\hline 4 & $\begin{array}{c}\text { Oficina de Conteúdo por meio de Roda de } \\
\text { Conversa com preleções curtas contextuali- } \\
\text { zadas (em terra) sobre: a) Composição da } \\
\text { Geobiodiversidade; b) Exemplo de Teia Ali- } \\
\text { mentar Submarina }\end{array}$ & Ausente & Presente \\
\hline 5 & $\begin{array}{l}\text { Verificação de tamanho adequado de más- } \\
\text { cara de mergulho, respirador e pés de pato }\end{array}$ & \multicolumn{2}{|c|}{ Presente } \\
\hline 6 & $\begin{array}{c}\text { Transporte da balsa com o material de mer- } \\
\text { gulho pelos participantes para o ponto de } \\
\text { partida na praia arenosa }\end{array}$ & \multicolumn{2}{|c|}{ Presente } \\
\hline 7 & Aquecimento físico & \multicolumn{2}{|c|}{ Presente } \\
\hline 8 & $\begin{array}{l}\text { Oficina de sensibilização fora d'água com } \\
\text { contemplação do mar e solicitação de uma } \\
\text { palavra que expressasse essa emoção }\end{array}$ & Ausente & Presente \\
\hline 9 & $\begin{array}{l}\text { Oficina de sensibilização dentro d'água com } \\
\text { colocação do material de mergulho nos eco- } \\
\text { turistas }\end{array}$ & \multicolumn{2}{|c|}{ Presente } \\
\hline 10 & $\begin{array}{l}\text { Percurso na trilha em pontos interpretativos, } \\
\text { abordando: a) identificação da geobiodiver- } \\
\text { sidade; b) observação de inter-relações trófi- } \\
\text { cas importantes; c) diálogo sobre questões } \\
\text { socioambientais com efeitos globais/locais; } \\
\text { d) síntese integradora final }\end{array}$ & \multicolumn{2}{|c|}{ Presente } \\
\hline 11 & Aplicação de Pós-Teste via entrevista & Ausente & Presente \\
\hline 12 & $\begin{array}{c}\text { Realização de entrevista para avaliação da } \\
\text { atividade }\end{array}$ & Ausente & Presente \\
\hline 13 & $\begin{array}{c}\text { Retorno dos monitores, por mar, ao ponto } \\
\text { inicial de saída, empurrando a balsa e o } \\
\text { material de mergulho emprestado aos ecotu- } \\
\text { ristas }\end{array}$ & \multicolumn{2}{|c|}{ Presente } \\
\hline
\end{tabular}

A fase 1 teve um detalhamento maior na inscrição na medida em que, tratandose de uma pesquisa a caracterização do entrevistado é essencial para configurar suas respostas. No entanto, em se tratando de um produto comercial é desejável que haja sempre um levantamento prévio das características básicas do ecoturista. O EcoTurisMar apresentou diferenças em relação ao padrão TrilhaSub nas seguintes características: a) na fase 2 a aplicação de um pré-teste foi fundamental para se tentar mapear o conhecimento prévio detido pelo ecoturista em função do que seria oferecido a ele na atividade; além disso configurou a linha de base para a comparação posterior 
com os resultados de pós-teste. O TrilhaSub não realiza permanentemente essa fase devido à grande demanda de ecoturistas que visitam o PEIA em janeiro em busca do projeto. E também porque essa pesquisa já foi feita no início de suas atividades, demonstrando eficácia da proposta (BERCHEZ, et al., 2005); b) a fase 4 é um dos diferenciais do EcoTurisMar, pois são apresentados ainda em terra dois pôsteres, sendo um deles com fotografias coloridas sobre a geobiodiversidade do PEIA (GHILARDI, et al., 2007) e o outro com um exemplo possível de teia trófica marinha contextual, envolvendo grande parte da geobiodiversidade apresentada no pôster anterior; c) na fase 8 a proposta EcoTurisMar apresentou uma atividade de sensibilização antes da que foi realizada dentro do mar, baseada nos preceitos de Diaz (2007), o qual enseja que haja a introdução do lúdico na EA. A atividade compreendeu a contemplação do mar por 1 minuto pelo ecoturista e sua expressão em uma palavra da emoção que tomou conta dele ao fitá-lo; d) a fase 11 possibilita que os resultados do pós-teste sejam comparados com os do pré-teste, possibilitando a avaliação de desempenho dos ecoturistas; e) a avaliação final da atividade é fundamental para se registrar se foram atingidos os objetivos da atividade.

\subsection{Avaliação}

A adoção de pré e pós-testes tem sido muito utilizada em trabalhos de EA em triIhas, variando apenas os roteiros que podem ser aplicados através de entrevistas (PADUA, 2004). A entrevista de pré-teste visa mapear o conhecimento pretérito do participate quanto ao que ele receberia na atividade e a de pós-teste quanto ao que ele pode sentir em termos de emoção e reter em termos de informação. Na entrevista de pré-teste foi feita breve caracterização do participante e na de pós-teste foi feita também uma avaliação da atividade como um todo.

A estratégia avaliativa foi realizada através de entrevistas realizadas ao início (PréTeste) da atividade e ao seu final (Pós-Teste). As questões adotadas para a avaliação basearam-se num roteiro semi-estruturado com questões constantes no Quadro IV.

A Teia da Vida (TV) vem sendo adotada com eficácia na avaliação de atividades de EA através da medição do número de conexões como forma de medição de acréscimos da geobiodiversidade por Pedrini e De-Paula (2008). Sinteticamente pode ser definida pela solicitação para que o entrevistado apontasse quais macrocompartimentos possuíam relações de dependência entre si. No presente trabalho, os macrocompartimentos listados foram: a) corais, b) peixes, c) algas, d) água do mar, e) homem f) sol, g) ar, h) plâncton. $O$ ideal desejado era que o participante respondesse que todos os compartimentos se relacionavam entre si.

As respostas das entrevistas foram lançadas numa planilha e sintetizadas na forma de números relativos (\%), visando à caracterização dos participantes e a avaliação da atividade em termos gerais. Para as questões que se repetiram em ambas as entrevistas foi utilizado o teste estatístico não-paramétrico pareado de Wilcoxon Mann-Whitney com o auxílio do software SPSS 12.0, com o objetivo de verificar possíveis alterações de conceitos/atitudes nos participantes. Para essas questões, foi considerado para comparação o número absoluto de vezes em que a alternativa/resposta foi mencionada em cada uma das entrevistas. 
Pedrini, A.G.; Messas, T.P.; Pereira, E.S.; Ghilardi-Lopes, N.P.; Berchez, F.A.

Quadro IV - Questões constantes no roteiro semi-estruturado do pré e pós-teste.

\begin{tabular}{|c|c|c|c|c|c|}
\hline Questão & \multicolumn{5}{|c|}{ Possibilidades oferecidas de respostas } \\
\hline $\begin{array}{l}\text { O que é meio } \\
\text { ambiente? }\end{array}$ & $\begin{array}{l}\text { Natureza } \\
\text { tipo mata, } \\
\text { mar }\end{array}$ & $\begin{array}{c}\text { Natureza } \\
\text { com huma- } \\
\text { nos }\end{array}$ & $\begin{array}{l}\text { Lugar exclusi- } \\
\text { vo para huma- } \\
\text { nos }\end{array}$ & Outro & \\
\hline $\begin{array}{l}\text { Como o mar } \\
\text { contribui para o } \\
\text { equilíbrio ambi- } \\
\text { ental do plane- } \\
\text { ta? }\end{array}$ & $\begin{array}{l}\text { mantém o } \\
\text { equilíbrio } \\
\text { do clima }\end{array}$ & $\begin{array}{l}\text { é responsá- } \\
\text { vel pelas } \\
\text { chuvas }\end{array}$ & $\begin{array}{l}\text { produz o oxi- } \\
\text { gênio que res- } \\
\text { piramos }\end{array}$ & $\begin{array}{l}\text { produz to- } \\
\text { dos os nos- } \\
\text { sos alimen- } \\
\text { tos }\end{array}$ & Outro \\
\hline \multirow{2}{*}{$\begin{array}{l}\text { O que você } \\
\text { vê como im- } \\
\text { pacto negativo } \\
\text { no meio mari- } \\
\text { nho?/O que } \\
\text { contribui para } \\
\text { tornar ruim o } \\
\text { mar como nes- } \\
\text { sa praia? }\end{array}$} & $\begin{array}{l}\text { esgoto das } \\
\text { casas }\end{array}$ & $\begin{array}{l}\text { lixo dos tu- } \\
\text { ristas }\end{array}$ & $\begin{array}{l}\text { tocar e mexer } \\
\text { nas plantas e } \\
\text { animais }\end{array}$ & $\begin{array}{l}\text { óleo do bar- } \\
\text { co que Ihe } \\
\text { trouxe e } \\
\text { visita a ilha }\end{array}$ & $\begin{array}{l}\text { usar o pé } \\
\text { de pato e } \\
\text { fazer baru- } \\
\text { lho ao na- } \\
\text { dar }\end{array}$ \\
\hline & $\begin{array}{ll}\text { boiar na } \\
\text { água }\end{array}$ & $\begin{array}{l}\text { ficar olhan- } \\
\text { do para os } \\
\text { bichos e } \\
\text { plantas }\end{array}$ & outra & & \\
\hline \multirow{5}{*}{$\begin{array}{l}\text { O que existe no } \\
\text { mar e você a- } \\
\text { cha que tem } \\
\text { aqui? }\end{array}$} & algas & corais & peixes & água & $\begin{array}{l}\text { ouriço do } \\
\text { mar }\end{array}$ \\
\hline & camarão & areia & caranguejo & golfinho & polvo \\
\hline & tartaruga & tubarão & baleia & moreia & lagosta \\
\hline & pedras & cracas & mexilhão & plâncton & lula \\
\hline & $\begin{array}{l}\text { minhoca- } \\
\text { marinha }\end{array}$ & $\begin{array}{l}\text { estrela do } \\
\text { mar }\end{array}$ & Água-viva & outro & \\
\hline $\begin{array}{l}\text { Para que serve } \\
\text { a EA dirigida } \\
\text { para o mar? }\end{array}$ & \multicolumn{5}{|c|}{ Sem oferta de possibilidades de resposta } \\
\hline $\begin{array}{l}\text { Você sabe o } \\
\text { que fazer para } \\
\text { a conservação } \\
\text { do mar? }\end{array}$ & \multicolumn{5}{|c|}{ Sem oferta de possibilidades de resposta } \\
\hline \multirow{3}{*}{$\begin{array}{l}\text { Que comparti- } \\
\text { mentos depen- } \\
\text { dem entre si? }\end{array}$} & \multicolumn{5}{|c|}{ Sol } \\
\hline & \multicolumn{2}{|c|}{ Animais como Peixes } & & \multicolumn{2}{|l|}{ Plâncton } \\
\hline & & & $\operatorname{Ar}$ & \multicolumn{2}{|c|}{ Animais como Corais } \\
\hline
\end{tabular}




\section{Resultados e Discussão}

\subsection{Caracterização dos Entrevistados}

Um total de 46 pessoas foi entrevistado. Destas, 25 (54,35\%) eram do sexo masculino e 21 (45,65\%), do sexo feminino. A idade dos participantes variou de 15-60 anos. Quanto à escolaridade dos participantes, dois possuíam apenas o ensino fundamental, 11 possuíam ensino médio, 27 o ensino superior e 5 possuíam especialização. Dentre os que possuíam ensino superior, foram mencionados 11 diferentes cursos de graduação, evidenciando a grande diversidade de formação do público frequentador da atividade e a importância da capacitação dos monitores para atingir esses diferentes públicos.

Do total de entrevistados, 25 (54,35\%) já havia visitado uma Unidade de Conservação, sendo que 22 já haviam visitado o PEIA e 4 já haviam participado do Projeto TrilhaSub. Tais dados sugerem que esse projeto ainda não alcançou a maioria dos ecoturistas que visitam o PEIA, apesar de estar presente lá há cerca de 8 anos ininterruptamente $e$ fazer parte da programação do Projeto do governo estadual intitulado "Trilhas de São Paulo". O ideal seria o PEIA e a Fundação Florestal do estado de São Paulo se apropriarem dessa metodologia e produto de EAM e oferecê-los regularmente o ano inteiro. Ideal seria ainda se pudessem promover o envolvimento comunitário com os principais atores sociais do PEIA como os escuneiros, filhos da ilha, funcionários terceirizados e estatutários, pescadores, etc. A Trilha Subaquática do PEIA é a única atividade gratuita organizada cientificamente numa trilha marinha em todo o Brasil.

\subsection{A sensibilização terrestre da atividade}

Durante a sensibilização fora d'água, foram mencionadas pelos participantes 22 diferentes palavras para expressar a emoção que sentiam ao observar o mar, sendo "Paz", "Tranquilidade", "Vida" e "Lindo" as mais citadas (Tabela 1).

Tabela 1 - Palavras citadas pelos participantes da atividade EcoTurisMar durante a fase de sensibilização pré-atividade com as respectivas quantidades em porcentagem.

\begin{tabular}{|l|c|l|c|}
\hline \multicolumn{1}{|c|}{ Palavra } & Citações em porcentagem & \multicolumn{1}{c|}{ Palavra } & Citações em porcentagem \\
\hline Paz & 15 & Liberdade & 2,5 \\
\hline Tranquilidade & 12,5 & Grandeza & 2,5 \\
\hline Vida & 12,5 & Leveza & 2,5 \\
\hline Lindo & 10 & Maravilha & 2,5 \\
\hline Beleza & 7,5 & Mar & 2,5 \\
\hline Bonito & 2,5 & Paixão & 2,5 \\
\hline Amor & 2,5 & Poder & 2,5 \\
\hline Brisa & 2,5 & Perfeito & 2,5 \\
\hline Esperança & 2,5 & Relaxante & 2,5 \\
\hline Extraordinário & 2,5 & Respeito & 2,5 \\
\hline Força & 2,5 & Riqueza & \\
\hline
\end{tabular}


Pedrini, A.G.; Messas, T.P.; Pereira, E.S.; Ghilardi-Lopes, N.P.; Berchez, F.A.

Como observado na Tabela 1 cerca de $28 \%$ das expressões foram da sensação de paz e tranquilidade com cerca de $18 \%$ para sentimentos de beleza, ou seja, cerca de $50 \%$ foram centradas em paz/tranquilidade/beleza. Heemann e Heemann (2003) apontam que percepção contemplativa da natureza traduz a significação de paz tradicionalmente, aqui representada pelo mar. Esse tipo de percepção pelos sentidos em trilhas tem sido muito adotada por educadores ambientais como Matarezi (2006) com grande sucesso e não deve ser descartado na EASS.

\subsection{Avaliação}

\subsubsection{Conceito de Meio Ambiente (MA)}

A Figura 3 mostra que a maioria entrevistada já tinha previamente o conceito de MA globalizante (REIGOTA, 2007) o que era desejado e esse fato praticamente se manteve. Porém, observou-se uma diferença significativa (aumento) apenas no número de pessoas que o entenderam como lugar exclusivo para humanos $(p=0,005)$, o que pode ser considerado um efeito indesejado/não esperado da atividade, uma vez que a intenção era a de transmitir a ideia de "sustentabilidade compartilhada", que apesar de ser um conceito antropocêntrico em seu cerne (BAKER et al., 1997), preconiza a responsabilidade coletiva na utilização dos recursos naturais, ou seja, o ser humano como organismo dependente da natureza para a sobrevivência e juntamente com a mesma integrando o meio ambiente.

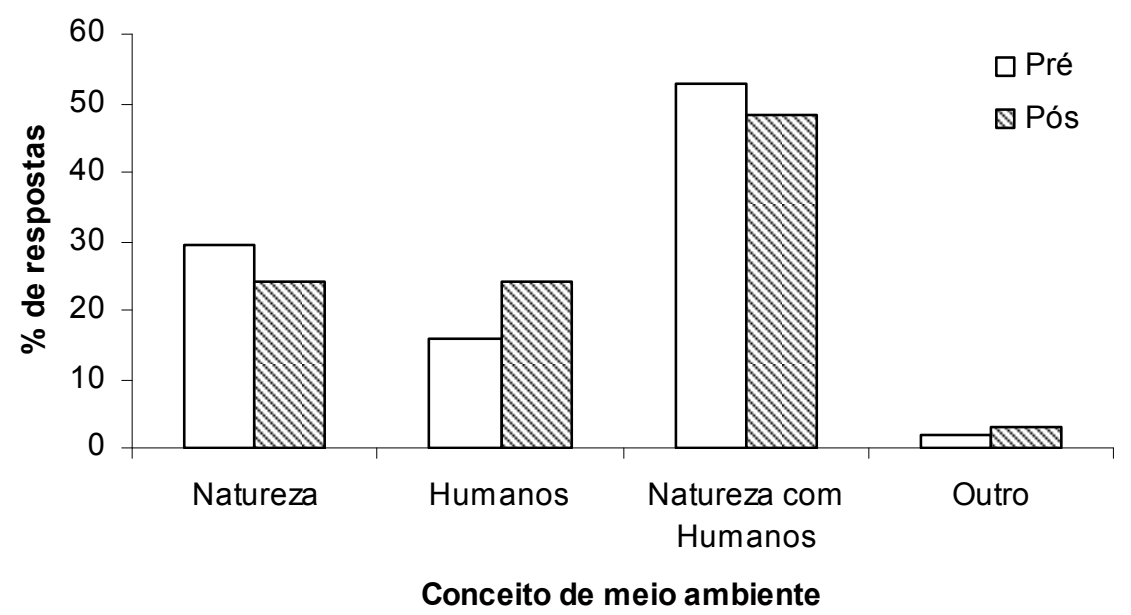

Figura 3 - Número de respostas, em porcentagem, assinaladas pelos participantes do Projeto EcoTurisMar nas entrevistas pré (em branco) e pós (hachurado) teste aplicadas em janeiro de 2010, referente ao conceito de meio ambiente.

\subsubsection{Contribuição do mar para o equilíbrio ambiental do planeta}

Quando questionados sobre a contribuição do mar para o equilíbrio ambiental do planeta (Figura 4), houve uma diminuição do número de alternativas assinaladas 
na entrevista pós-teste, sendo que na entrevista pré-teste foram assinaladas 9 das 10 alternativas oferecidas e no pós-teste foram apontadas apenas 4 . Houve aumento significativo no número absoluto de vezes em que a alternativa "Respiração" foi assinalada na entrevista pós-teste $(p=0,001)$. As demais alternativas não apresentaram alterações significativas $(p>0,05)$. Os resultados mostram que, de fato, a concentração de respostas na respiração mostrou que os ecoturistas perceberam que as microalgas dependem do mar em ótimas condições para que todos possam respirar o oxigênio que elas produzem em excesso. Desse modo, a aglutinação das respostas nesse quesito foi um evento muito interessante, pois a mídia/publicações técnicas tem se prendido apenas a mostrar o mar como controlador do clima.

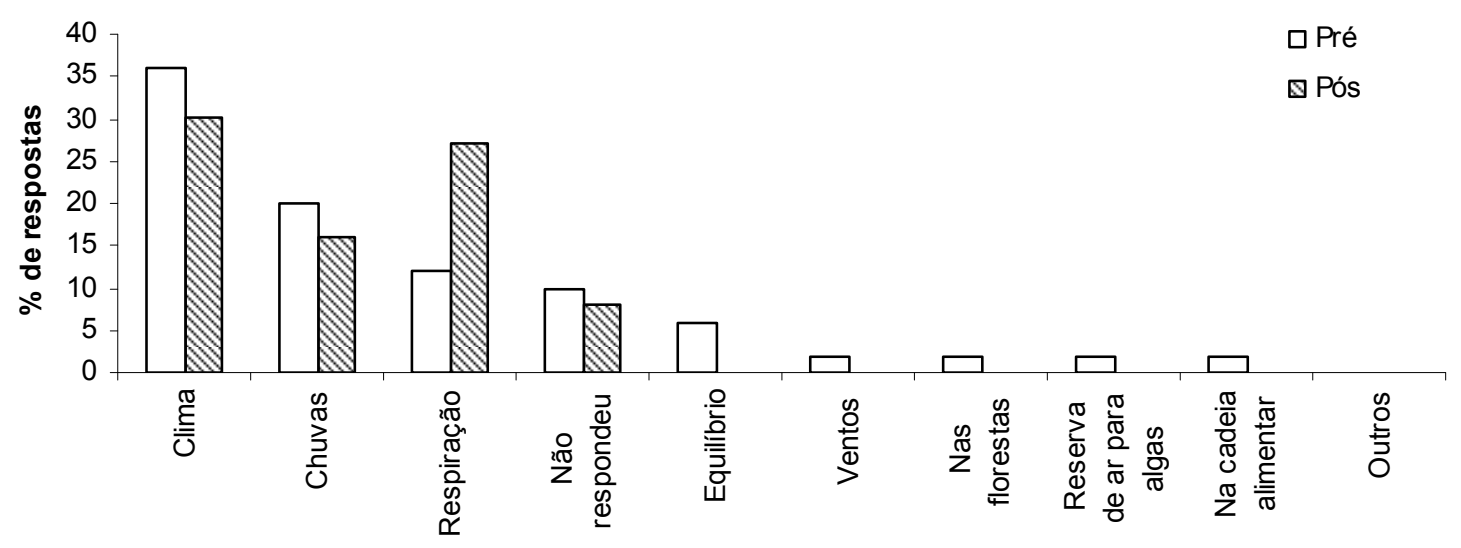

Influência do mar sobre o planeta

Figura 4 - Número de respostas, em porcentagem, assinaladas pelos participantes do Projeto EcoTurisMar nas entrevistas pré (em branco) e pós (hachurado) teste aplicadas em janeiro de 2010, referente contribuição do mar para o equilíbrio do planeta.

\subsubsection{Componentes que faziam parte do ambiente marinho}

A mesma tendência foi observada quando os participantes foram questionados sobre os componentes que faziam parte do ambiente marinho (Figura 5). Nesse caso na entrevista pré-teste foram apontadas 27 das 29 alternativas oferecidas e no pósteste apenas 22. Houve diminuição significativa no número absoluto de vezes em que as alternativas "Plâncton" $(p=0,046)$, "Camarão" $(p=0,014)$, "Lula" $(p=0,014)$, "Caranguejo" $\quad(p=0,008)$, "Lagosta" $\quad(p=0,008), \quad$ "Água Viva" $\quad(p=0,005)$, "Polvo" ( $p=0,003)$, "Tartaruga" $(p=0,002)$ e "Mexilhão" $(p=0,000)$ foram apontadas. Houve aumento significativo no número absoluto de vezes que a alternativa "Craca" $(p=0,008)$ foi assinalada, possivelmente por ser um organismo facilmente visualizado na área percorrida pelos participantes durante a atividade por se localizar no mediolitoral próximo a sua visão.

Essa concentração evidenciou que o imaginário dos ecoturistas era de que o 
Pedrini, A.G.; Messas, T.P.; Pereira, E.S.; Ghilardi-Lopes, N.P.; Berchez, F.A.

ambiente marinho de uma UC teria uma diversidade biológica similar ao que eles aprenderam na escola e no senso comum. Ou seja, que o PEIA como uma UC seria um lugar macrodiverso e não sofresse qualquer tipo de impacto negativo. No entanto, a passagem pela trilha mostrou que a própria trilha já apresenta sinais de um (eco) turismo predatório.

A Figura 5 também mostra que ocorreu um sensível aumento no número de vezes que alguns organismos que ocorrem fixos no costão foram mencionados, em detrimento daqueles que podem se movimentar ou vivem na massa d'água, ou seja, daqueles que não puderam ser vistos na visita à trilha marinha.Vale destacar o componente "Algas Marinhas", pois tal como foi apontado por Pedrini et al. (2008b) tanto a campanha de 2008 no PEIA como a de 2010 conseguiram mostrar sua ocorrência na trilha marinha. É comum haver confusão por parte de ecoturistas sobre o que se traduz como algas marinhas sob a água, havendo superposição entre algas e corais (OIGMAN-PSZCZOL, et al., 2007).

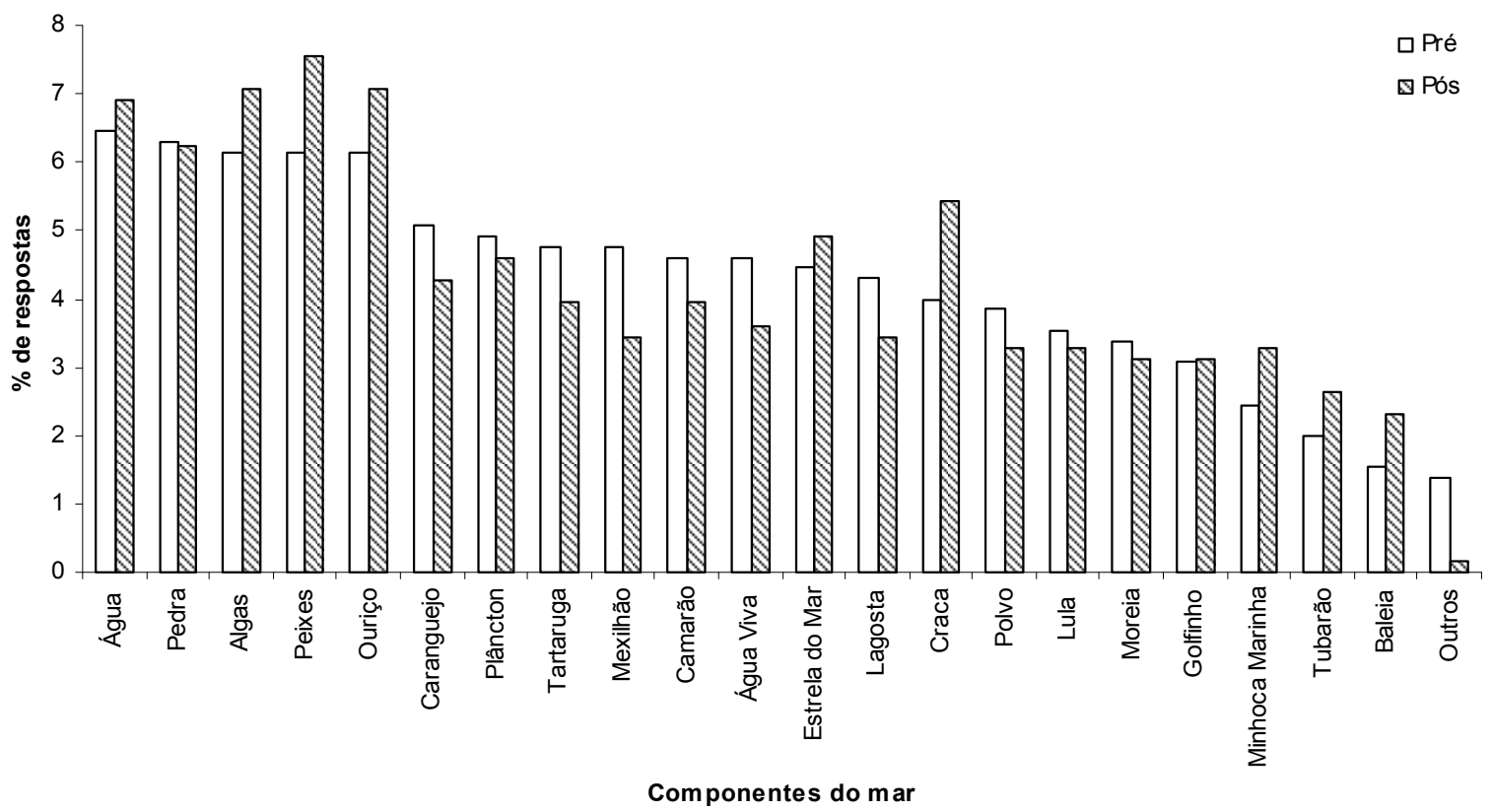

Figura 5 - Número de respostas, em porcentagem, assinaladas pelos participantes do Projeto EcoTurisMar nas entrevistas pré (em branco) e pós (hachurado) teste aplicadas em janeiro de 2010 , referente aos componentes que fazem parte do ambiente marinho.

\subsubsection{Impactos negativos causados no mar}

Quando perguntados sobre os impactos negativos causados no mar (Figura 6), os entrevistados mencionaram 11, sendo que nesse caso não lhes foram apresentadas alternativas pré-estabelecidas. O impacto mais citado foi "Poluição", tanto na en- 
trevista pré (36 vezes) quanto no pós-teste (32 vezes), tendo inclusive aumentado em termos proporcionais (de $41,4 \%$ para $48,5 \%$ do total de respostas dadas nas entrevistas, respectivamente). Houve redução significativa no número absoluto de vezes que as alternativas "Acidentes Ambientais" $(p=0,005)$, "Pesca Predatória" $(p=0,008)$ e "Aquecimento Global" $(p=0,008)$ foram mencionadas e houve um aumento significativo no número absoluto de vezes em que a resposta "Degradação Humana" $(p=0,046)$ foi mencionada. As respostas "Movimentação de pessoas na água" e "Tsunami" só foram mencionadas na entrevista pré-teste e a resposta "Turismo", apenas no pósteste.

Tais resultados sugerem que o ecoturista já tem uma forte noção de que a poluição e a degradação (em conjunto) causadas por serem humanos impacta negativamente o mar.

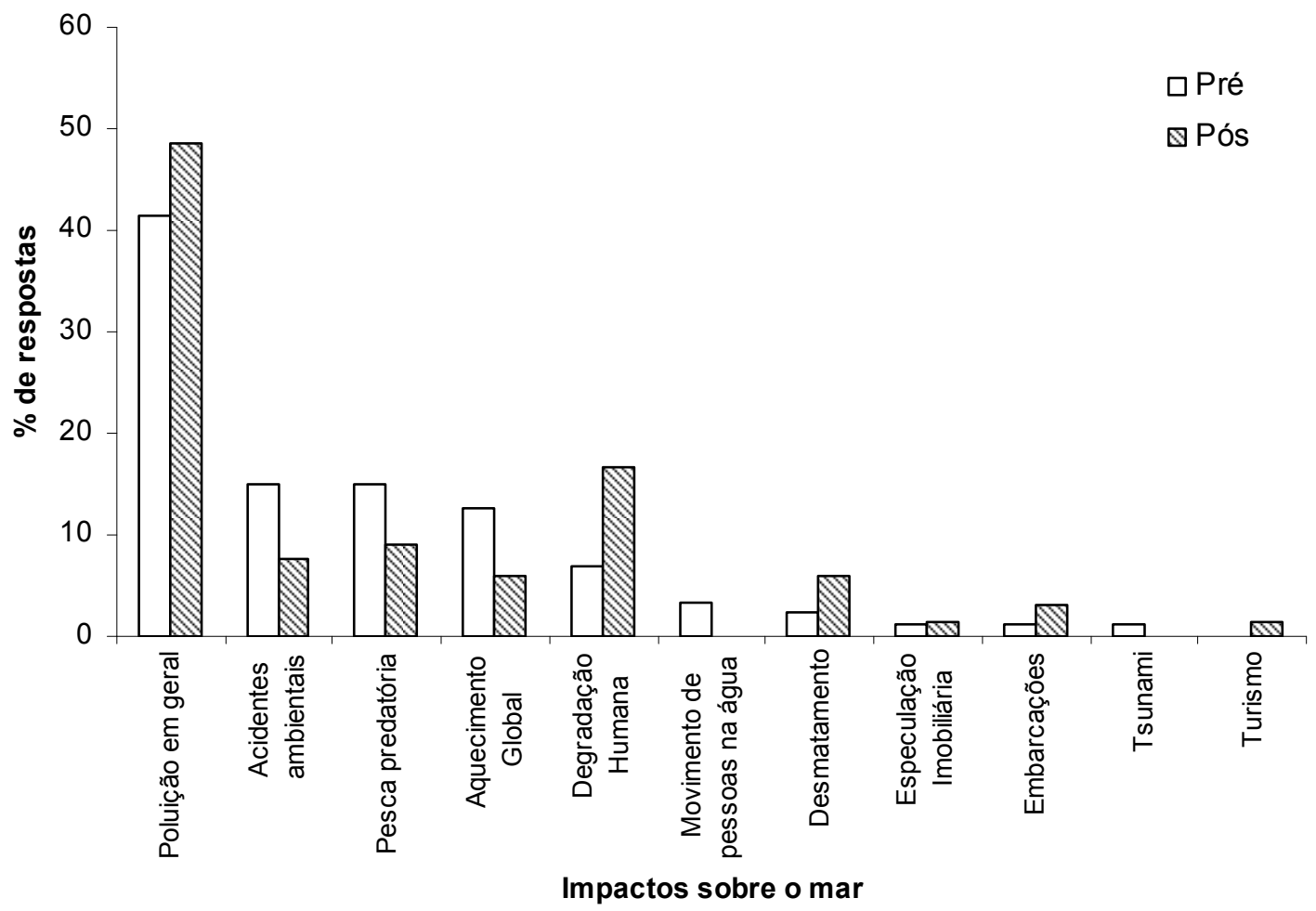

Figura 6 - Número de respostas, em porcentagem, assinaladas pelos participantes do Projeto EcoTurisMar nas entrevistas pré (em branco) e pós (hachurado) teste aplicadas em janeiro de 2010, referente aos impactos causados no ambiente marinho.

\subsubsection{Impactos ambientais observados no PEIA}

Em relação aos impactos ambientais observados na área do Parque (Figura 7) os participantes mencionaram principalmente "Lixo", "Esgoto", "Óleo" e "Tocar e me- 
Pedrini, A.G.; Messas, T.P.; Pereira, E.S.; Ghilardi-Lopes, N.P.; Berchez, F.A.

xer", tanto na entrevista pré quanto no pós-teste, sem alterações significativas referentes a estes ítens em ambos. Não houve diferenças significativas nos demais itens, os quais foram mencionados em menor quantidade. As alternativas "Pesca Descontrolada" e "Desequilíbrio" só foram mencionadas na entrevista pré-teste e as alternativas "Olhar", "Falta de Instrução", "Turismo" e "Liberação das praias" foram mencionadas apenas na do pós-teste.

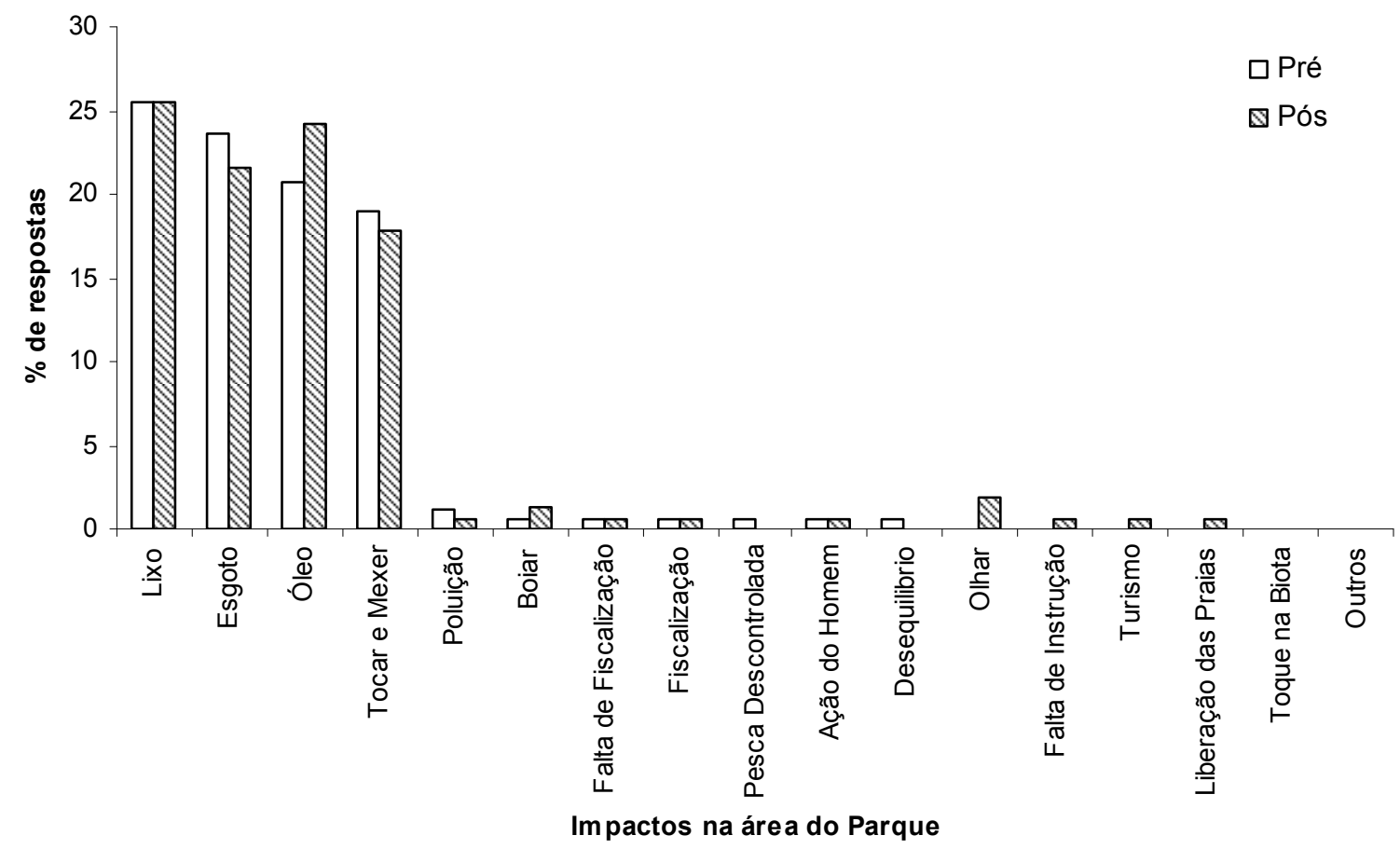

Figura 7 - Número de respostas, em porcentagem, assinaladas pelos participantes do Projeto EcoTurisMar nas entrevistas pré (em branco) e pós (hachurado) teste aplicadas em janeiro de 2010, referente aos impactos observados na área do PEIA.

É interessante notar a percepção de que os ecoturistas mostraram quanto a saberem que tocar e mexer nos organismos marinhos é considerado um impacto negativo. Geralmente, os impactos negativos do senso comum são os mais citados por eles, ou seja, lixo, esgoto e o óleo dos motores das escunas que os levaram ao PEIA. Houve também um acréscimo no quesito olhar aos organismos que tradicionalmente o ecoturista não imaginava que causaria impacto negativo, já que ele não tocaria nos organismos. Porém, trabalhos recentes mostram que determinadas espécies de peixes ao visualizar mergulhadores fogem, como o sargentinho (Abudefduf saxatilis), e outras não, como o salema (Anisotremus taeniatus), fazendo com que uma espécie de peixe se aproveite da fuga de outra e se alimente dos ovos do ninho do peixe que fugiu (LUIZ Jr., 2007). E todos sabemos que os animais marinhos como peixes e polvos se assustam e/ou fogem ao verem o homem. 


\subsubsection{Medidas para minimização dos impactos no ambiente marinho}

Os participantes deram diversas sugestões para minimização dos impactos no ambiente marinho, principalmente "Diminuição da Poluição" que foi marcada mais vezes tanto na entrevista pré (21 vezes ou $31,34 \%$ do total de respostas assinaladas nesta entrevista) quanto no pós-teste (15 vezes ou $26,32 \%$ do total de respostas assinaladas nesta entrevista), mesmo tendo havido uma queda significativa de um para outro $(p=0,014)$. Houve redução significativa no número absoluto de vezes que a alternativa "Não degradar" foi assinalada $(p=0,025)$. Houve ainda aumento significativo no número absoluto de vezes que a alternativa "Preservar" foi assinalada $(p=0,025)$, que apesar de interessante no caso de áreas com restrição de uso, vai contra a noção de utilização sustentável dos recursos naturais. As demais alternativas não apresentaram alterações significativas em termos absolutos nas duas entrevistas.

É interessante comentar que os ecoturistas passaram a ter a noção de que é meIhor preservar/conservar (para eles são a mesma coisa) e aumentar a conscientização pública, diminuindo a antropização negativa. Ou seja, sugerem proteger o que ainda resta e implementar ampla educação ambiental pública.

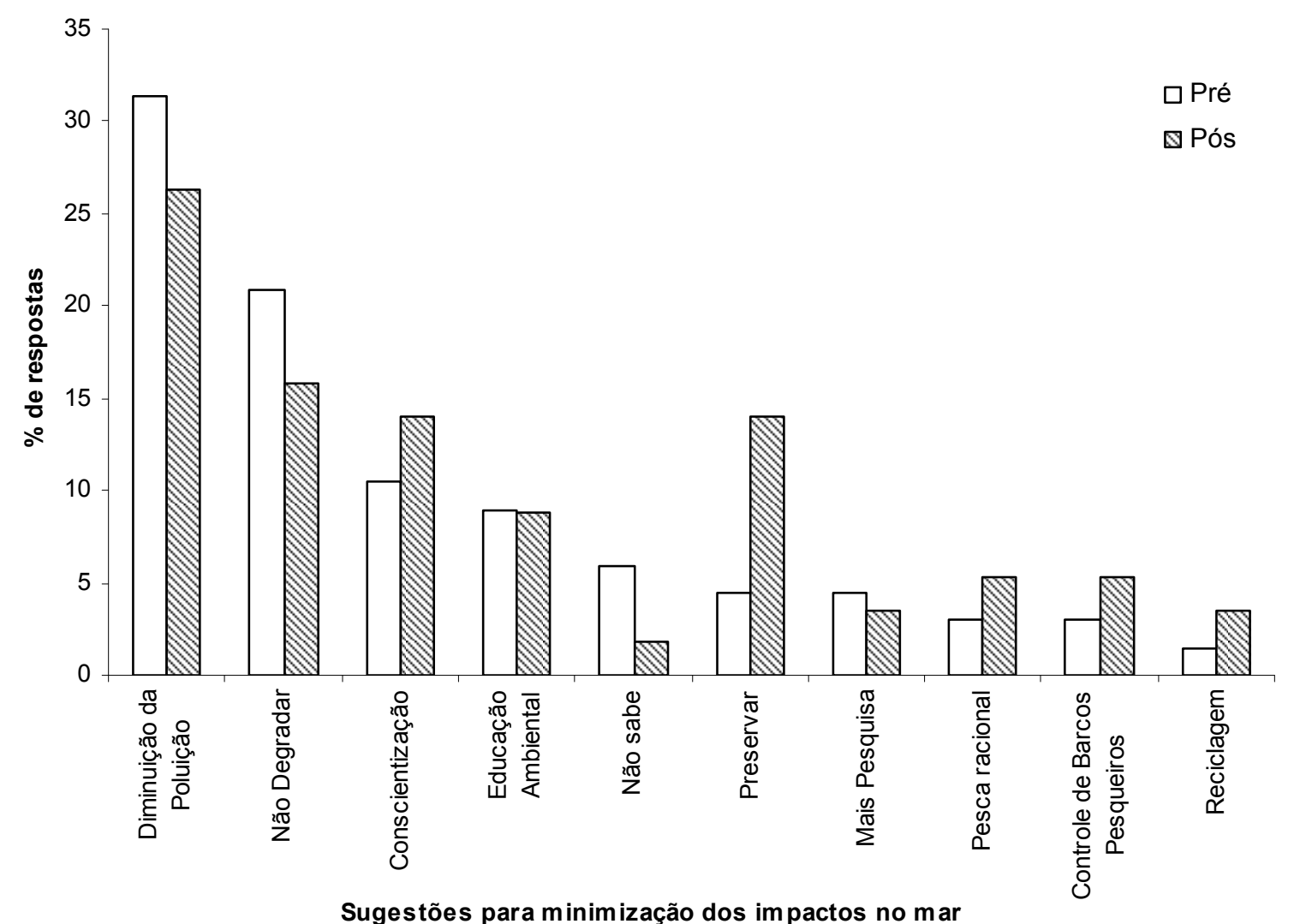

Figura 8 - Número de respostas, em porcentagem, assinaladas pelos participantes do Projeto EcoTurisMar nas entrevistas pré (em branco) e pós (hachurado) teste aplicadas em janeiro de 2010, referente às sugestões para a minimização dos impactos no ambiente marinho. 
Pedrini, A.G.; Messas, T.P.; Pereira, E.S.; Ghilardi-Lopes, N.P.; Berchez, F.A.

\subsubsection{Conceito de Educação Ambiental Marinha}

Quanto ao conceito de Educação Ambiental para o mar (Figura 9), observou-se uma diferença na quantidade de alternativas assinaladas pelos participantes nas entrevistas pré e pós-teste, sendo que na primeira foram assinaladas 10 alternativas diferentes e na segunda, apenas 7. A alternativa mais assinalada foi "Preservação/ Conservação" (18 vezes ou $33,33 \%$ do total de alternativas assinaladas na entrevista pré-teste e 23 vezes ou $46,94 \%$ do total no pós-teste), com um aumento significativo no pós-teste $(p=0,025)$.

Esses resultados confirmam a tendência dos ecoturistas verificada no item anterior quando Ihes foi perguntado sobre que medidas tomariam para enfrentar o impacto negativo sobre o mar. Ou seja, propuseram preservação das áreas a serem preservadas/conservadas, seguida de conscientização ambiental pública, diminuindo a quantidade de ecoturistas que não sabiam o que fazer.

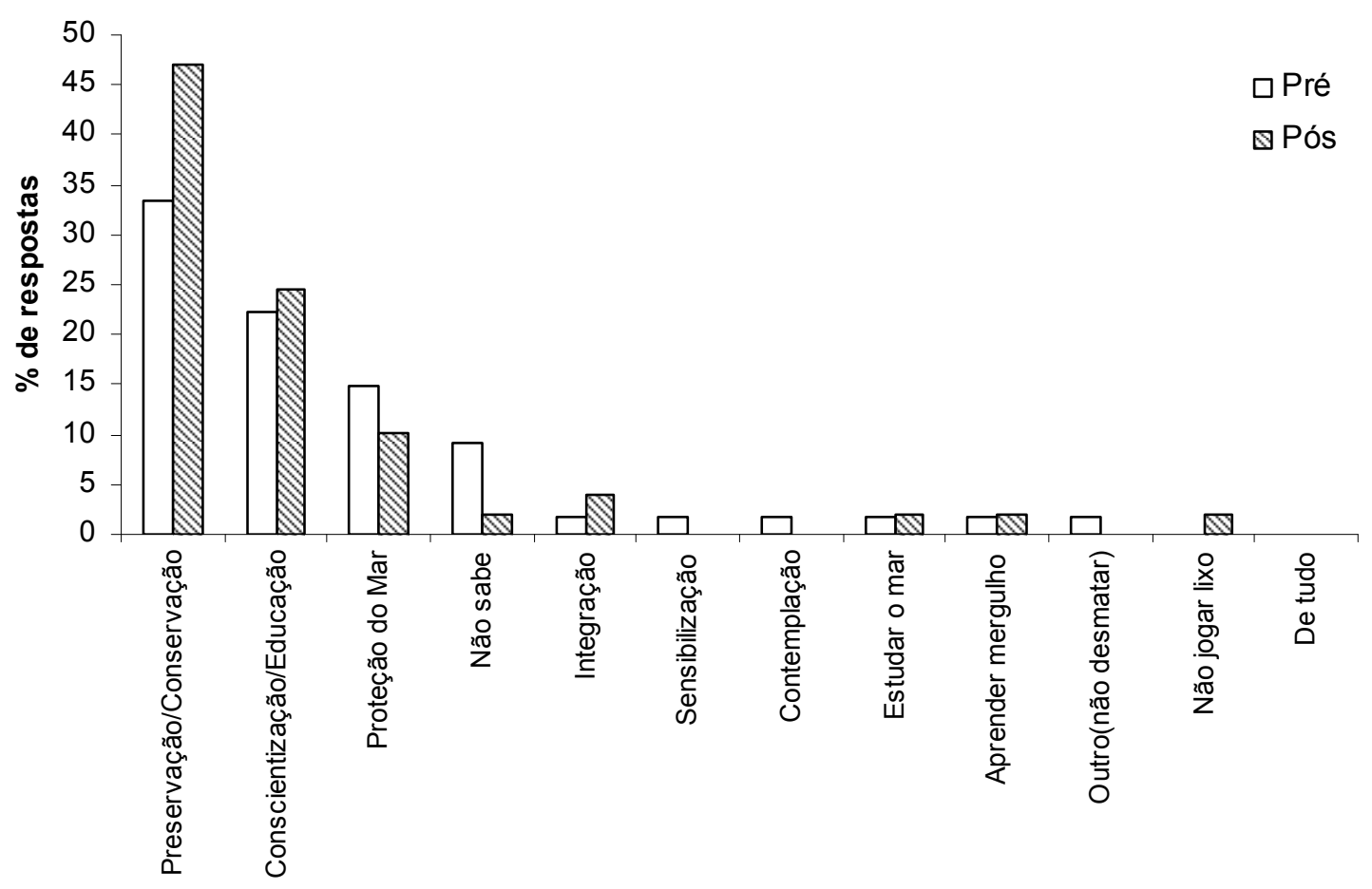

Conceito de Educação Ambiental dirigida para o mar

Figura 9 - Número de respostas, em porcentagem, assinaladas pelos participantes do Projeto EcoTurisMar nas entrevistas pré (em branco) e pós (hachurado) teste aplicadas em janeiro de 2010, referente ao conceito de educação ambiental dirigida para o mar. 


\subsubsection{Número de conexões entre os compartimentos socioambientais}

$\mathrm{Na}$ teia da vida, houve aumento no número de conexões totais respondidas para todos os compartimentos socioambientais e para o total de conexões entre pré e pós-teste $(p=0,000)$, o que indica que a atividade permitiu aos participantes entender melhor a relação entre os diferentes componentes do meio ambiente, ou seja, o meio ambiente como um sistema em que cada uma das partes desempenha papel importante para o funcionamento do todo. Houve também aumento em cada um dos compartimentos de modo individualizado sem haver um deles com maior destaque que outro, sugerindo a percepção de que tudo se relaciona com tudo e não há compartimento mais importante. Pedrini et al. (2009) também obtiveram acréscimos totais no número de conexões, mostrando que esse indicador é capaz de evidenciar a capacidade de expressar a percepção do conjunto que traduz o conceito de totalidade do meio ambiente.

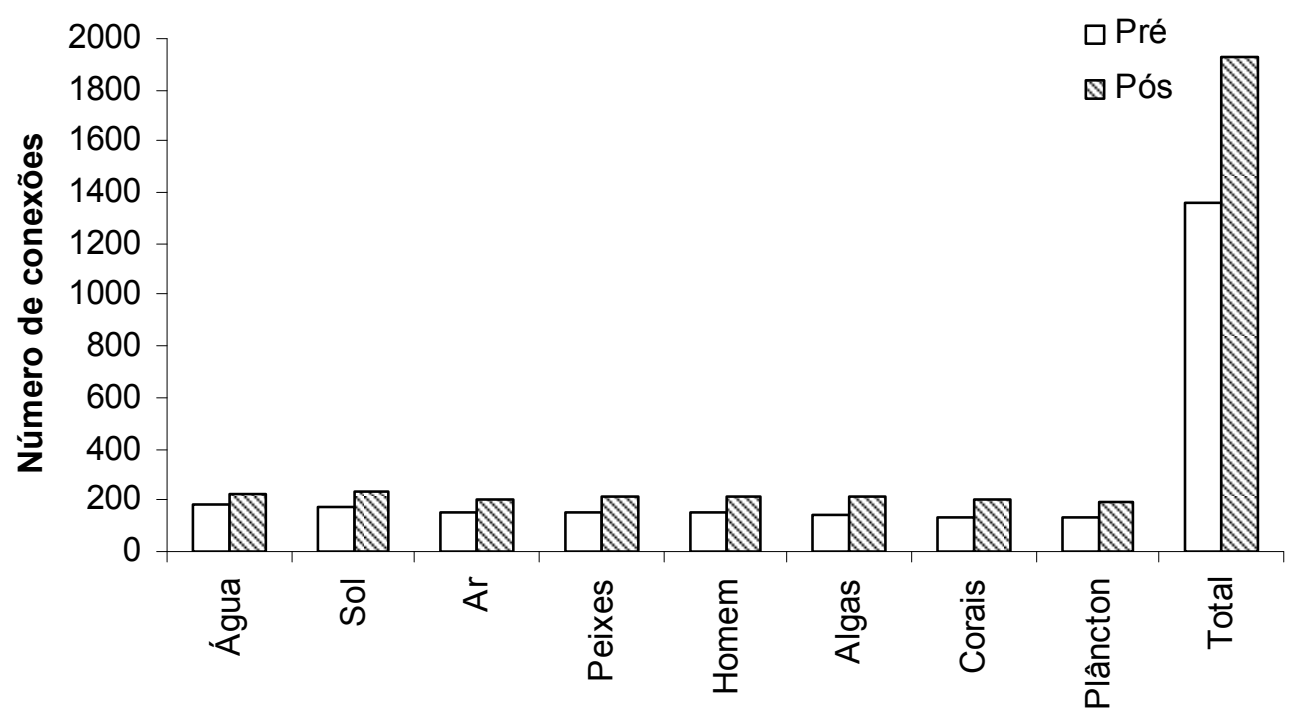

Componente da teia da vida

Figura 10 - Número de conexões envolvendo os diferentes componentes da teia da vida assinaladas pelos participantes do Projeto EcoTurisMar nas entrevistas pré (em branco) e pós (hachurado) teste aplicadas em janeiro de 2010).

\subsubsection{Avaliação da atividade pelos ecoturistas}

Quando questionados sobre o que mais haviam gostado na atividade as alternativas foram assinaladas 66 vezes e os participantes responderam em primeiro lugar as paradas ou pontos interpretativos ( $51,52 \%$ das respostas), em segundo lugar a sensibilização $(25,75 \%)$ e em terceiro os pôsteres $(22,73 \%)$. Em relação ao que me- 
nos haviam gostado, as alternativas foram assinaladas apenas 9 vezes, sendo que os pôsteres foram assinalados 5 vezes $(55,55 \%)$, a sensibilização foi assinalada 3 vezes $(33,33 \%)$ e a alternativa "outras" foi assinalada 1 vez $(11,11 \%)$.

Em relação aos monitores a avaliação foi positiva, sendo que as alternativas dadas foram assinaladas 87 vezes pelos participantes. Os monitores foram considerados claros em suas explanações $(31,03 \%$ das respostas), simpáticos $(31,03 \%)$, objetivos $(29,88 \%)$, humildes $(4,60 \%)$ ou perfeitos $(1,10 \%)$. Apenas $2,3 \%$ das respostas indicaram os monitores como confusos.

Em relação à avaliação geral da atividade, a mesma foi avaliada como excelente pela maioria dos entrevistados $(75,55 \%)$, ou ainda como ótima $(17,77 \%)$, boa $(4,44 \%)$ ou regular $(2,22 \%)$ pelos demais. Dentre as sugestões, oito participantes apontaram para o aumento no tempo da atividade, 3 acharam a divulgação deficitária e 1 sugeriu ampliar a fase de capacitação para o mergulho

\section{Considerações Finais}

Segundo Berchez et al. (2007), atividades de EAM devem ser conceitual e operacionalmente bem embasadas, dentro de modelos educacionais definidos e testados, para que seu potencial não seja subutilizado e para que não provoquem ações contrárias às efetivamente esperadas, como por exemplo, impactos negativos no ambiente. Não é fácil avaliar o sucesso de uma atividade de EAMC, pois o efeito causado no visitante não será sentido no local da atividade. A EA é um processo de reflexão e seus resultados aparecem no cotidiano daquele que sofreu a influência deste tipo de iniciativa. A atividade de EASS numa trilha ecoturística precisa ter condições adequadas para sua prática. A avaliação da qualidade conceitual da EASS (se o conceito for equivocado todo o processo certamente o será também) numa trilha interpretativa segundo cada contexto de um percurso deve apresentar atributos conceituais, adaptados dos principais pressupostos pedagógicos do TEASS.

A atividade Ecoturismar acrescentou à atividade-base do TrilhaSub a sensopercepção e os baneres contextuais da geobiodiversidade que juntas agradaram em cerca de $49 \%$ aos ecoturistas. O restante $(51 \%)$ coube às paradas interpretativas que é uma atividade tradicional de trilhas interpretativas/educativas como já mencionadas por Wegner (2002) e Berchez et al. (2005) e cuja eficácia já é conhecida (COSTA, 2006; NEIMAN, 2007).

A avaliação efetuada no presente trabalho permitiu a identificação de acertos e desacertos no processo da presente pesquisa. Os acertos podem ser apresentados: a) aumento significativo $(p=0,001)$ da percepção da contribuição do mar através das microalgas que nele vivem pela disponibilização do excesso de oxigênio que elas produzem para a respiração de outros seres existentes no planeta; b) alteração da préconcepção dos ecoturistas sobre a biodiversidade em uma UC e a maior percepção de organismos do costão como as macroalgas e os ouriços; c) aumento significativo $(p=0,046)$ da percepção da "Degradação Humana" como principal impacto negativo 
no mar; d) noção do ecoturista de que os principais impactos negativos do PEIA eram tanto de origem tecnológica (Lixo, Esgoto e Óleo) como do próprio ecoturista ao tocar e mexer nos organismos marinhos; e) aumento significativo $(p=0,025)$ da percepção de "Preservação/conservação" como forma de minimizar o impacto ambiental negativo humano e como principal atividade da EASS; f) aumento significativo $(p=0,000)$ no número de conexões para cada compartimento socioambiental e no seu total, indicando entendimento da interdependência desses.

A atividade realizada foi positivamente avaliada pelos participantes que creditaram aos monitores, na maioria absoluta dos casos, alto grau de profissionalismo, competência e simpatia. No entanto, alguns pontos devem ser observados em separado e ressaltados, apesar de que no conjunto as visões individualizadas foram superadas: a) o conceito antropocêntrico de meio ambiente que foi adquirido por alguns participantes; b) a diminuição na compreensão do papel que o mar representa para o equilíbrio do planeta; c) a redução no número de componentes do ambiente marinho citados após a atividade; d) a redução no número de vezes que alguns impactos causados no mar foram mencionados; e) a redução significativa no número de vezes em que as alternativas para minimização do impacto "Diminuir a poluição" e "Não degradar" foram mencionadas e o viés preservacionista que ficou evidente ao final da atividade; f) a redução do número de conceitos associados à EA voltada para o mar ao final da atividade.

Os desacertos foram essencialmente quanto às limitações de tempo dos ecoturistas no PEIA, causando efeito "bola de neve" aos entrevistadores que faziam as entrevistas acelerados. Os desacertos podem ser explicados, provavelmente, pelo seguinte: a) priorização na obtenção de maior número de entrevistados (aumentando o número de entrevistas) em detrimento de maior tempo para comunicação e obtenção de dados/informações; b) tempo limitadíssimo do ecoturista que só pode permanecer no PEIA por até duas horas (a atividade durava cerca de uma hora e meia e as pessoas não tinham tempo para responder as entrevistas do pós-teste no tempo planejado); c) tempo inadequado de capacitação dos monitores do TrilhaSub para desenvolverem a atividade do projeto EcoTurisMar; d) roteiro semi-estruturado para entrevista muito extenso. É incomum em resultados de pesquisas se apontar equívocos no processo de pesquisa e assim esse resultado preliminar sobre a metodologia a ser desenvolvido no mar subsidiará a capacitação dos monitores do Projeto EcoTurisMar. No PEIA os monitores foram aqueles capacitados basicamente para a atividade de EASS pelo Mergulho Livre na Trilha Subaquática Marinha que de fato foi a base essencial da proposta do EcoTurisMar.

Uma questão importante que já foi mencionada por Orams (1997) e Luck (2003) e que pode influenciar muito os resultados das entrevistas é quanto ao interesse dos ecoturistas em aprender sobre as questões ambientais no seu trajeto ecoturístico e tomar consciência socioambiental pelas preleções da atividade de EA. Nos seus trabalhos sobre ecoturismo de observação de golfinhos marinhos a maioria dos ecoturistas disse que gostaria de aprender durante a atividade. No entanto, alguns disse- 
ram que não e se isso ocorreu durante nossa pesquisa explicaria porque algumas perguntas não foram respondidas. Percebeu-se durante as entrevistas que alguns ecoturistas respondiam às perguntas de má vontade e mal-humorados. Nas perguntas em que havia sugestões de respostas (algumas erradas e isso era comunicado ao ecoturista para evitar aceitar todas as possibilidades) eles respondiam rapidamente $e$ não se concentravam adequadamente. Desse modo, é difícil se esperar dos ecoturistas reativos qualquer mudança como as pretendidas pela EASS. Apenas ecoturistas proativos poderão acrescentar informações e ter ricas vivências e assim dar um salto de qualidade para que se possa perceber o ambiente sob um novo prisma e mudar seus hábitos, posturas e condutas e pensar uma sociedade sustentável e mais equânime à humanidade.

E, por fim, além das questões acima citadas, pode ter havido problemas na comunicação entre monitor-ecoturista, face às limitações do tempo. Porém, é importante considerar que o monitor tem de ser um intérprete da mensagem que se deseja transmitir e tem de criar uma empatia entre ele e o seu grupo, recriando a magia do educador primitivo, o contador de histórias (PILETTI; PILETTI, 1995). Para a transferência de conceitos formativos, ou seja, aqueles que visam à mudança de comportamento, 0 monitor deve atuar como modelo, pois é ele que dá o exemplo a ser seguido (HADEL, 2010) e, por isso, deve estar plenamente consciente do papel que representa para o grupo que acompanha. Sua responsabilidade não é apenas repetir conceitos aprendidos na sua capacitação teórica, mas contextualizar o máximo suas preleções. Porém, é durante essa atividade prática que é refletida ao final de cada dia por seus supervisores que o monitor vai sendo forjado e continuamente aperfeiçoado. Assim, a diferença de propósitos entre os projetos pode também ter influenciado, ou seja, pelo TriIhaSub de capacitar na prática monitores de EAM e do EcoTurisMar de testar uma de suas propostas de metodologia de EASS para o ecoturismo.

O presente artigo apresentou uma proposta de Educação Ambiental para Sociedades Sustentáveis através de uma atividade que será posteriormente incluída num produto ecoturístico marinho. A proposta do Projeto EcoTurisMar se parece com a atividade de Educação Ambiental Marinha do Projeto TrilhaSub da Universidade de São Paulo, diferindo por possuir atividades de sensopercepção da contemplação do mar e uma fase de comunicação de informações contextuais sobre a geobiodiversidade e uma teia alimentar marinha, envolvendo elementos abióticos e bióticos.

O objetivo de testar a EASS aliada a uma proposta de ecoturismo marinho calcada numa atividade de EA na Trilha Marinha do PEIA - um dos produtos pedagógicos do TrilhaSub/USP - foi factível. As análises com foco avaliador permitiram identificar mais acertos que imperfeições. Mais testes são necessários no contexto onde será desenvolvido o produto EcoTurisMar que tenciona envolver a comunidade local e gerar renda para os atores sociais envolvidos, sendo o presente trabalho o relato de uma das abordagens planejadas para a trilha marinha. 


\section{Referências Bibliográficas}

AMARAL, A. C. Z.; JABLONSKI,S. Conservation of marine and coastal biodiversity in Brazil. Conservation Biology, v. 19, p. 625-631, 2005.

AUGUSTOWSKI, M.; FRANCINE Jr, R. O mergulho recreacional como ferramenta para o turismo sustentável em unidades de conservação marinhas. In: CONGRESSO BRASILEIRO DE UNIDADES DE CONSERVAÇÃO, 3., 2002, 1 v., Anais..., p. 443452.

BARBOSA, M. A. C.; ZAMBONI, R. A. Formação de um cluster em torno do turismo de natureza sustentável em Bonito (MS). In: TIRONI, L. F. (Org.) Industrialização Descentralizada: sistemas industriais locais. Rio de Janeiro: Ministério do Planejamento, Orçamento e Gestão/Instituto de Pesquisa Econômica Aplicada, 2001, p. 451498.

BAKER, S.; KOUSIS, M.; RICHARDSON, D.; YOUNG, S. The politics of sustainable development: theory, policy and practice within the European Union. London: Routledge, 1997. 261p.

BARROS, M. I. A. de; DINES, M. Mínimo impacto em áreas naturais: uma mudança de attitude. In: SERRANO, C. (Org.) A Educação pelas Pedras: Ecoturismo e Educação Ambiental. São Paulo: Chronos, 2000. p. 47-84.

BERCHEZ, F.; CARVALHAL, F.; ROBIM, M. J. Underwater interpretative Trail - guidance to improve education and decrease ecological damage. International Journal of Environment and Sustainable Development, v. 4, n. 2, p. 128-139. 2005.

BERCHEZ, F.; GHILARDI, N.; ROBIM, M. de J.; PEDRINI, A. de G.; HADEL, V. F.; FLUKIGER, G.; SIMÕES, M.; MAZZARO, R.; KLAUSENER, C.; SANCHES, C.; BESPALEC, P. Projeto trilha Subaquática - Sugestão de diretrizes para a criação de modelos de Educação Ambiental para ecossistemas marinhos. Revista OLAM, Ciência e Tecnologia, Rio Claro (SP), v.7, n. 2, p. 181-208, 2007.

BRASIL. Programa Nacional de Educação Ambiental - ProNEA. Brasília: Ministério do Meio Ambiente. 2005. 102 p.

CERVANTES, A. L. A.; BERGAMASCO, A.; CARDOSO, C. J.; AOKI, H.; MOTA, I. S.; ADAMENAS, J.; FONTES, M. A.; ROBIM, M. J.; TABANEZ, M. F.; HERCULANI, S. Diretrizes para os programas de uso público do Instituto Florestal do Estado de São Paulo - SMA. In: CONGRESSO NACIONAL SOBRE ESSENCIAS NATIVAS, 2., 1992, Anais..., , v. 4, p. 1076-1080.

CORIOLANO, L. N. T., ARAÚJO, A. M. M., VASCONCELOS, F. P.; ALMEIDA, H. M. de; ROCHA, A. M.; GONÇALVES, A.; LIMA, A. C. G., QUINTILIANO, A. B., SAMPAIO, C. F., MENDES, E. G., NASCIMENTO, I. V. O.; GONÇALVES, M. M. de P., NETO, 
Pedrini, A.G.; Messas, T.P.; Pereira, E.S.; Ghilardi-Lopes, N.P.; Berchez, F.A.

G. F., BARBOSA, L. M., SOUZA, E. A. L. de, SALES, E. A., PARENTE, K. M. N., RODRIGUES, T. da C. Arranjos Produtivos Locais do Turismo Comunitário: Atores e Cenários em Mudança. Fortaleza: EdUECe, 2009. 312 p.

COSTA, V. C. da C. Propostas de Manejo e Planejamento Ambiental de Trilhas Ecoturísticas: Um Estudo no Maciço da Pedra Branca - Município do Rio de Janeiro (RJ). 2006. 325 f. Tese (Doutorado em Geografia) - Universidade Federal do Rio de Janeiro, Rio de Janeiro, 2006.

COSTA, V. C. da C.; COSTA, N. M. C. Educação Ambiental pelo Ecoturismo em Unidades de Conservação: uma proposta efetiva para o Parque Estadual da Pedra Branca-RJ. In: PEDRINI, A de G.(Org.) Ecoturismo e Educação Ambiental. Rio de Janeiro: Publit, 2005. p. 39-65.

DELGADO, J. A Interpretação Ambiental como Instrumento para o Ecoturismo. In: SERRANO, C.M.T.; (Org.) A educação pelas pedras: ecoturismo e educação ambiental. São Paulo: Chronos, 2000, p. 155-169.

DIAZ, P. Aplicação do lúdico em Educação Ambiental. In: PEDRINI, A. de G. (Org.) Metodologias em Educação Ambiental. Petrópolis: Vozes, 2007, p. 95-125.

FIGUEIREDO, J. A V. de. Ecoturismo e participação popular no manejo de áreas protegidas: aspectos conceituais, educativos e reflexões. In: RODRIGUES, A B.(Org.) Turismo e Ambiente: reflexões e propostas. São Paulo: HUCITEC, 1999, p. 55-67.

GALLO NETO, H.; BARBOSA, C. B. Educação Ambiental em Aquários de Visitação Pública: A experiência do Aquário de Ubatuba. In: PEDRINI, A. de G. (Org.) Educação Ambiental Marinha e Costeira no Brasil. Rio de Janeiro: Eduerj, 2010 (no prelo).

GHILARDI, N. P.; BERCHEZ, F. Projeto Trilha Subaquática-Modelos de Educação Ambiental Marinha. In: PEDRINI, A. de G. (Org.) Educação Ambiental Marinha e Costeira no Brasil. Rio de Janeiro: Eduerj, 2010 (no prelo).

GHILARDI-LOPES, N. P.; HADEL, V. F.; BERCHEZ, F. Guia para Educação Ambiental em Costões Rochosos. São Paulo: Associação Projeto Ecossistemas Costeiros, 2007. $95 \mathrm{p}$.

GOUVEIA, M. T. J. (Org) Educação para conservação de recifes: Manual de capacitação do professor em Educação Ambiental. Projeto Coral Vivo. Rio de Janeiro. 2008.

HADEL, V.F., 2010. Programa de Visitas ao Centro de Biologia Marinha-USP: o monitor na mediação entre a Academia e o grande público. In: PEDRINI, A. de G. (Org.) Educação Ambiental Marinha e Costeira no Brasil. Rio de Janeiro: Eduerj, 2010 (no prelo). 
HEEMANN, A.; HEEMANN, N. Natureza e percepção de valores. Desenvolvimento e Meio Ambiente, n. 7, p. 109-112, jan./jun. 2003.

HINTZE, H.C. Ecoturismo na Cultura de Consumo: possibilidade de educação ambiental ou espetáculo?. Revista Brasileira de Ecoturismo, São Paulo, v.2, n.1, p.57100. 2008.

HONEY, M. Ecotourism and Sustainable Development: Who Owns Paradise?. Washington, D.C.: Island Press, 1999, p. 22-23.

KAWAMOTO Jr, L. T. Mitigação de impactos decorrentes de mergulhos. In: ENGEMA - ENCONTRO NACIONAL SOBRE GESTAO EMPRESARIAL E MEIO AMBIENTE, 8., nov.2005, Rio de Janeiro, Anais...,15 p.

LIMA, M. L. P.; SCHMIDT, A., CHAMAS, C. C., WEGNER, E. Implantação de Trilhas Subaquáticas Guiadas na Ilha do Campeche, Florianópolis-Sc. In: ENCONTRO NACIONAL DE GERENCIAMENTO COSTEIRO, 1., Florianópolis, 2006, Anais..., Agência Brasileira de Gerenciamento Costeiro, 2006, 4 p.

LUCK, M. Education on marine mammal tours as agent for conservation-but do tourists want to be educated? Ocean \& Coastal Management, v. 46, p. 943-956, 2003.

LUIZ Jr., O. Interações entre mergulhadores autônomos e peixes recifais aumenta a taxa de predação sobre Abdudefduf saxatilis, In: ENCONTRO BRASILEIRO DE ICTIOLOGIA, 17., 2007, Itajaí, Resumos..., UNIVALI/SC.

MACHADO, G. E. M. Subsídios para implantação de uma trilha subaquática na Enseada do Cambury - Núcleo Picinguaba: Parque Estadual da Serra do Mar (UbatubaSP). 2007. 52 f. Monografia (Especialização em Ciências Ambientais) -Universidade Federal do Rio de Janeiro, Rio de Janeiro. 2007.

MADIN, E. M. P.; FENTON, D. M. Environmental Interpretation in the Great Barrier Reef Marine Park: An Assessment of Programme Effectiveness. Journal of Sustainable Tourism, v. 12, n. 2, p. 121-137, 2004.

MATAREZI, J. Despertando os sentidos da educação ambiental. EDUCAR em Revista, Curitiba, n. 27, p. 181-199. Jan-Jun 2006.

MELO, R. S.; CRISPIM, M. C. e LIMA, E. R. V. O turismo em ambientes recifais: em busca da transição para a sustentabilidade. Caderno Virtual de Turismo, Rio de Janeiro, v. 5, n. 4, p. 34-42. 2005.

MILLER, M. L. The Rise of Coastal and Marine Tourism. Ocean \& Coastal Management, v. 20, p. 181-199, 1993. 
Pedrini, A.G.; Messas, T.P.; Pereira, E.S.; Ghilardi-Lopes, N.P.; Berchez, F.A.

MITRAUD, S. F. (Coord.) Uso recreativo no Parque Nacional Marinho de Fernando de Noronha: um exemplo de planejamento e implementação. Brasília: WWF, 2001, 100 p.

NEIMAN, Z. Contato dirigido com a natureza como instrumento de Educação Ambiental. 2007. 152 f. Tese (Doutorado em Psicologia) - Curso de Pós-Graduação em Psicologia, Universidade de São Paulo, São Paulo, 2007.

NOEBAUER, D. A. Instrumento para avaliação de pesquisas e programas de educação ambiental em unidades de conservação. Estudo de caso do Parque Natural Municipal das Nascentes do Garcia, Blumenau, SC. 2004. 98 f. Dissertação (Mestrado em Engenharia Ambiental), Universidade Regional de Blumenau, Programa de Pós Graduação em Engenharia Ambiental, Blumenau, 2004.

OIGMAN-PSZCZOL, S. S, OLIVEIRA, A. E. S., CREED. J. C Perceptions of coral in a coastal tourist town in Brazil. Coral Reefs, 26:667-670, 2007.

ORAMS, M. B. The Effectiveness of Environmental Education: Can We Turn Tourists into "Greenies"? Progress in Tourism and Hospitality Research, v. 3, p. 295-306, 1997.

PADUA, S. M. Educação ambiental como um instrumento de integração entre conservação e uso sustentável dos recursos naturais: o caso do Pontal do Paranapanema, São Paulo. 2004. 180 f. Tese (Doutorado em Política e Gestão Ambiental) - Centro de Desenvolvimento Sustentável, Universidade de Brasília, Brasília, 2004.

PEDRINI, A. G. Avaliação da educação ambiental no ecoturismo (em trilhas) no Brasil: uma proposta baseada na qualidade conceitual. OLAM Ciência e Tecnologia, Rio Claro (SP), v.6, n.2, p. 83-106. 2006.

PEDRINI, A de G. Um caminho das pedras em Educação Ambiental. In: PEDRINI, A de G. (Org.) Metodologias em Educação Ambiental. Petrópolis: Vozes, 2007, p. 2351.

PEDRINI, A. de G. Educação Ambiental Marinha e Costeira no Brasil; aportes para uma síntese. In: PEDRINI, A. de G. (Org.) Educação Ambiental Marinha e Costeira no Brasil. Rio de Janeiro: Eduerj, 2010 (no prelo).

PEDRINI, A. de G.; DE-PAULA, J. C. Educação Ambiental; Críticas e Propostas. In: PEDRINI, A. de G. (Org.) 6 ed. Educação Ambiental: Reflexões e Práticas Contemporâneas. Petrópolis: Vozes, 2008, p. 88-145. 
PEDRINI, A. de G ; ANDRADE-COSTA, E. ; SILVA, V. G. ; PINA, R. S. ; SABA, M. ; BERCHEZ, F. Projeto EcoTurisMar: Uma Proposta de Educação/Interpretação Ambiental para o Ecoturismo Marinho em Áreas Protegidas. Estudo de Caso Preliminar no Parque Estadual da llha Anchieta, São Paulo, Brasil. In: SEMANA NACIONAL DE OCEANOGRAFIA, 21., 2-8 de agosto de 2009, Belém, Anais..., 4 p., Aoceano.

PEREIRA, $P$. M. Sistematização das informações relativas às Unidades de Conservação das zonas costeira e marinha do Brasil. Manuscrito, 1999, 57 p.

PILETTI, J.; PILETTI, M. História da educação. São Paulo: Ática. 1995. 240 p.

PRATES, A. P. Unidades de Conservação. In: PRATES, A.P. (Org) Atlas de Recifes de Coral em Unidades de Conservação Brasileiras. Brasília: Ministério do Meio Ambiente. $2^{\mathrm{a}}$ edição, 2006, p. 31-35.

PRATES, A. P. L.; DUARTE, A. L. M.; FERREIRA, B. P.; GEORGI, C. LOIOLA, L.; HAZIN, M. C.; REINHART, M. H. PEREIRA, P. M. Conduta Consciente em Ambientes Recifais. Brasília: Ministério do Meio Ambiente, 2007, 28 p.

PRATES, A. P. L.; LIMA, L. H. de. Biodiversidade Costeira e Marinha. In: ZAMBONI, A.; NICOLODI, J. L. (Org.). Macrodiagnóstico da Zona Costeira a Marinha do Brasil. Brasília: Ministério do Meio Ambiente, 2008, p.196-203.

REIGOTA, M. Meio Ambiente e Representação Social. 7 ed. São Paulo: Cortez, 2007, $87 \mathrm{p}$.

REUSS-STRENGEL, G.; ASMUS, M.; CHLUDINSKI, A. P. Avaliação do impacto causado pelo turismo marinho na Reserva Biológica Marinha do Arvoredo, Santa Catarina, Brasil, utilizando um modelo ecológico de simulação. In: CONGRESSO BRASILEIRO DE UNIDADES DE CONSERVAÇÃO, 1., 1997, Curitiba: Anais...,. Rede Pró-UC, p.528-541.

RUSCHMANN, D. V. D. M. Impactos ambientais do turismo ecológico no Brasil. Turismo em Análise, São Paulo, v. 4, n. 1, p. 56-68, mai/1993.

SALES, E. J. C. G.; ANTONIO FILHO, F. D. Turismo e a problemática da inclusão/ exclusão socioespacial: um estudo exploratório em Armação de Búzios - RJ. In: SIMPÓSIO DE PÓS-GRADUAÇÃO EM GEOGRAFIA DO ESTADO DO SÃO PAULO (SIMPGEO), 1., 17-19 de outubro de 2008, Rio Claro (SP), Anais..., , UNESP, p. 1122-1140.

SERRANO, C. A educação pelas pedras; uma introdução. In: SERRANO, C.; (Org.) A Educação pelas Pedras: Ecoturismo e Educação Ambiental. São Paulo: Chronos, 2000, p. 7-24. 
Pedrini, A.G.; Messas, T.P.; Pereira, E.S.; Ghilardi-Lopes, N.P.; Berchez, F.A.

SERRANO, C.; PAES-LUCHIARI, M. T. D. (Eco) turismo e Meio Ambiente no Brasil: Territorialidades e Contradições. In: TRIGO, L. G. G. (Ed.) Análises regionais e globais do Turismo Brasileiro. São Paulo: Roca, 2005, p. 505-515.

SILVA-JR., J. M; GERLING, C.; VENTURI, E.; LEITE, L.; LIMA Jr, W. L.; SILVA, F. J. de L. Projeto Férias Ecológicas: uma proposta de Educação Ambiental Marinha no Arquipélago de Fernando de Noronha, Brasil. www.sp.senac.br/professores: PEDRINI, A. de G. (Org.) Educação Ambiental Marinha e Costeira no Brasil.Rio de Janeiro: Eduerj, 2010(no prelo).

STEINER, A. Q.; ELOY, C. C.; AMARAL, J. R. B. C.; AMARAL, F. D.; SASSI, R. O turismo em áreas de recifes de coral: considerações acerca da Área de Proteção Ambiental Costa dos Corais (estados de Pernambuco e Alagoas). Revista OLAM - Ciência e Tecnologia, Rio Claro (SP), v. 6, n. 2, p. 261-296. 2006.

TABANEZ, M. F.; PADUA, S. M.; SOUZA, M. das G. de; CARDOSO, M. M.; GARRIDO, L. M. do A. G. Avaliação de trilhas interpretativas para Educação Ambiental. In: PADUA, S.M.; TABANEZ, M. F. (Org.) Educação Ambiental: caminhos trilhados no Brasil. Brasília: IPÊ, 1997, p. 89-102.

VASCONCELLOS, J. M. de O. 1998. Avaliação da visitação pública e da eficiência de diferentes tipos de trilhas interpretativas no Parque Estadual Pico do Marumbi e Reserva Natural do Salto Morato, Paraná. Tese (Doutorado em Ciências Florestais) - Universidade Federal do Paraná, Curitiba.1998.

VICTAL, J. L. Projeto Berçários Marinhos; disponível em: http://barcoescolabemar. blogspot.com/2008/11/; acesso em: 14/02/2010.

WEGNER, E. Proposta metodológica para implantação de trilhas subaquáticas na llha João da Cunha, Porto Belo SC. 2002. 112 f. Dissertação (Mestrado em Turismo) Centro de Educação Superior Balneário Camboriú, UNIVALI, Itajaí. 2002.

\section{Agradecimentos}

À Nara Garcia pelo desenho preliminar da teia alimentar. Aos coordenadores e monitores do Projeto TrilhaSub da terceira semana de janeiro de 2010, especialmente André Pimentel, Lucimara Marcelino, Deborah Gutierrez e Kauê Senger. Aos monitores do TrilhaSub que também realizaram as entrevistas: Gabriela C. Silva, Paula Giroldo, Pedro Coelho, Silvia Gonsales, Juliane Bosshart e a todos os outros que ajudaram principalmente com críticas construtivas. Aos funcionários, especialmente Carlos Augusto Baccarin e a direção do PEIA pelas facilidades concedidas na ilha. À Maria de Jesus Robim pela autorização da inclusão do mapa. À UERJ e a USP pela ajuda nessa época de crise financeira. 
Alexandre de Gusmão Pedrini: Universidade do Estado do Rio de Janeiro. Email: pedrini@uerj.br

Link para o currículo Lattes: http://lattes.cnpq.br/6918956483557789

Tatiana Pinto Messas: Universidade do Estado do Rio de Janeiro.

Email: tatamessas@hotmail.com

Link para o currículo Lattes: http://lattes.cnpq.br/6180130371145288

Eugênia da Silva Pereira: Universidade do Estado da Bahia.

Email: eniagbi@hotmail.com

Link para o currículo Lattes: http://lattes.cnpq.br/7989598828631072

Natalia Pirani Ghilardi-Lopes: Universidade Federal do ABC.

Email: natalinoel@gmail.com

Link para o currículo Lattes: http://lattes.cnpq.br/8457066927181345

Flávio Augusto Berchez: Universidade de São Paulo.

Email: fberchez@.usp.br

Link para o currículo Lattes: http://lattes.cnpq.br/3324554734888413

Data de submissão: 27 de fevereiro de 2010.

Data do aceite: 07 de maio de 2010. 